\title{
NUEVAS HIPÓTESIS Y AVANCES DE SELECCIÓN EN EL MEJORAMIENTO GENÉTICO DE PAPA Y CAMOTE PARA ADAPTACIÓN A SUELOS ÁRIDOS Y SALINOS
}

René Chávez A.', Mahesh Upadhya ${ }^{2}$, Humberto Mendoza ${ }^{3}$, Jorge Espinoza ${ }^{4}$, Rolando Cabello ${ }^{5}$, Porfirio Siles ${ }^{6}$, Giorgio Bollo ${ }^{6}$, Tomás Meléndez ${ }^{6}$, Julio Eyzaguirré, Carlos Maquera', Erwin Guevara7, Katya Monasterio".

\section{R E S U M E N}

\begin{abstract}
El descubrimiento de la variabilidad genética para resistencia a salinidad y sequía en el germoplasma hexaploide nativo y cullivares de camote $(2 x=6 x=90=B B B B B B)$ en poblaciones clonales tetraploides de papa $(2 x=4 x=48=A A A)$, a principios de 1985 , catalizo el inicio de una investigación aplicada sobre respuestas fenotipicas de las plantas tuberiferas a los estreses abióticos mâs comunes de las zonas âridas y salinas de potencial agricola de la costa del Pacífico. De esta manera. se estableció el mismo año el provecto de investigación colaborativa "Mejoramiento Genético de papa y camote para Zonas Aridas y Salinas, entre la Facultad de Ciencias Agricolas de la Universidad Nacional.Jorge Basadre Grohmann de Tacna (UN.BBG) y del Centro Internacional de la Papa. (CIP).
\end{abstract}

Dentro de la estrategia genética y logistica del provecto se diseñó un prosrama de cruzamientos y selecciones para generar clones y familias hibridas superiores, ast como progenitores de buena habilidad combinatoria, adaptados a las condiciones de aridez y salinidad de los suelos marginales de la costa del Pacifico. Este germoplasma mejorado, una vez liberado sería utilizado por los agricultores de esta zona agroecológica para la alimentación humana, como forraje y materia prima para la agroindustria.

Desde aquella fecha, hasta hoy en dia, se ha logrado una amplia ganancia genética y un extenso avance de selección, materializado fundamentalmente por un caudal de clones, hibridos y variedades superiores, adapradas a las condiciones climáticas y edaficas de los suelos costeros, asi como una amplia resistencia de campo al nemátodo del nudo de la raiz meloidogyne incognita (RKN), importante plaga de la papa y el camote en la costa y resistencia de campo a los principales virus patogenos de la papa con la finalidad de reducir el uso de plaguicidas químicos en los campos de cultivo.

\section{A B S T R A C T}

The discovery of genetic variability for resistance to salinity and drought among the hexaploid and native sweet potato germplasm $(2 n=6 X=90=B B B B B B)$, and in a tetraploid clonal potato population $(2 n=4 X=48=A A A A)$ in summer 1985, was a catalysis for the development of an applied research project on phenotypic responses of tuberiferous plants under abiotic stress conditions in arid lands and saline soils from the Pacific coastal areas. As a result of this, the same year, was established a collaborative research project on "BREEDING POTATOES AND SWEET POTATOES FOR ADAPTATION TO ARID AND SALINE SOIL CONDITIONS" between the Faculty of Agronomy of the National University of Tacna and the International Potato Center.

Within the genetic strategy and logistic of the project it was designed a breeding and screening program aimed to generate superior clones, hybrid families and progenitors with good combining ability adapted to arid and saline soil conditions with agricultural potential in the pacific coastal areas of South America. The improved germplasm, once released, would be utilized by farmers of this agroecological area for food, forage, and processing.

After eleven years of intensive research, there has been a broad and extensive advance of selection and genetic gain in the initial germplasm utilized at the beginning of this project. The accomplishment of the breeding and screening program can be described, besides the new and relevant technical information, in a generation of a gene pool with early superior clones, hybrids and released varieties with good agronomic attributes and tolerance to the most common abiotic stresses of the coastal areas. In addition to this, resistance to the root knot nematode (RKN), one of the most serious biotic soil stress, was incorporated in this new potato and sweet germplasm. Promising and advanced potato clones showing any symptoms of virus diseases were also discarded. This might result in the reduction of land contamination because the extensive use of insecticides. 


\section{I.INTRODUCCIÓN}

La creciente necesidad de agua de riego en las zonas agrícolas costeras y el avance de los cultivos hacia zonas marginales mayormente salinas, ha hecho que se preste una especial atención a la investigación sobre respuestas fenotípicas de las plantas a la salinidad y al estrés de sequia. En general, en los suelos áridos costeros, de potencial agricola, el estrés mineral diferente a la salinidad, es también la deficiencia de nitrógeno y fósforo, y el exceso de boro tóxico. Asimismo, las altas temperaturas de verano, para el caso particular de la papa, y las bajas temperaturas de invierno, para el camote, limitan la producción sostenida y el suministro permanente de materia prima para la agroindustria.

Durante once años de intensiva investigación genética en papa y camote, se condujieron más de 300 experimentos de campo. Se generaron más de 74000 genotipos, agrupados en 348 familias híbridas de camote. De esta población se identificaron más de 500 clones promisorios, de los cuales 75 fueron clasificados como superiores. De este grupo se seleccionaron diez clones precoces de mayor potencial agronómico, que fueron limpiados de virus e introducidos al sistema de cultivo in vitro. Ocho de estos clones fueron nominados y liberados como variedades superiores para ser utilizadas en la zona agroecológica costera.

Once años de investigación genética en papa generaron más de 25500 clones y familias hibridas promisorias de papa. De este material se seleccionaron 84 clones avanzados y 36 clones superiores muy precoces, adaptados a las condiciones áridas y salinas, y de alta calidad para la agroindustria. Seis clones superiores fueron limpiados de virus e introducidos al sistema de cultivo in vitro. De este grupo, dos clones fueron multiplicados, nominados y liberados para la zona costera. De todo el germoplasma mejorado, solamente seis clones superiores han mostrado también adaptación a las zonas semiáridas altoandinas (3000 msnm). Cuatro familias hibridas ya podrian ser usadas en la producción comercial de papa a partir de semilla botánica en zonas áridas con niveles bajos de salinidad. Actualmente, el germoplasma mejorado

1. M Sc., Ph D. Fitomejorador - Biotecnólogo. 2. M Sc., Ph D. Fisiólogo - Fitogenetista, CIP. 3. M Sc. Ph D. Fitomejorador Fitogenetista, CIP. 4. M Sc. Fitomejorador Genetista, CIP. 5. M Sc. Fisiólogo agrónomo, CIP. 6. B Sc. Agrónomo UNJBG. 7. M Sc. Nematólogo, CIP. 8. B Sc. Biotecnólogo. también incluye un grupo de 27 clones superiores de camote y 16 de papa con buena habilidad combinatoria para ser usados en el futuro, en la generación de progenies promisorias para seleccion clonal de las zonas áridas y salinas del Tercer Mundo.

\section{ASPECTOS AGROECOLÓGICOS DE LOS SUELOS ÁRIDOS Y SALINOS DE LA ZONA COSTERA}

Existen cerca de cinco millones de hectáreas de suelos áridos y salinos con potencial agrícola en la costa peruana. Sin embargo, actualmente, sólo una fracción de esta extensión es cultivada, debido a las condiciones extremas del suelo, como la salinidad, deficiente suministro de agua y niveles elevados de boro, que inhiben el desarrollo normal de las plantas y consecuentemente afectan la productividad de los cultivos. La sal dominante es el cloruro de sodio de origen marino, encontrándose en el suelo a niveles elevados que fluctúan entre 5 y $20 \mathrm{mmhs} / \mathrm{cm}$. y, en el caso del boro entre 4 y $10 \mathrm{ppm}$. Existiendo una variabilidad dinámica horizontal, vertical y temporal de la salinidad en los estratos edáficos, cuando éstos son irrigados.

Desde principios de 1985 se ha muestreado sistemáticamente y analizado cerca de 2000 muestras de suelos áridos. Las muestras se han colectado mayormente en tres zonas: a) suelos desérticos vírgenes b) suelos cultivados irrigados y c) suelos cultivados abandonados (sin riego). Asimismo, se realizaron numerosas calicatas para muestrear suelos en los diferentes horizontes, desde la superficie hasta $1.2 \mathrm{~m}$ de profundidad. Los resultados de los análisis de los suelos desérticos vírgenes, han sido sorprendentes, se ha detectado una enorme variabilidad horizontal y vertical de la concentración de sales en los estratos edáficos. Las franjas horizontales de salinidad pueden variar de 10 a 120 mmhs en pocos metros o kilómetros. La variabilidad vertical de los horizontes edáficos, es aun más conspicua, variando en algunos casos de 8 a $50 \mathrm{mmhs,}$ a pocos centímetros o decímetros. Asimismo, el contenido de boro puede variar de 4-10 ppm. y excepcionalmente de 4-14 ppm, como ocurre en los valles costeros de Sama y Locumba.

La dinámica del contenido de sales solubles en los suelos cultivados irrigados involucra, además de la variabilidad horizontal y vertical, la variabilidad temporal o estacional. En general, los niveles de salinidad bajan gradualmente a medida que se incrementa el numero de riegos (usualmente se irriga 
cada siete días). En muchos suelos áridos, el contenido de sales se incrementa a partir del primer día de riego hasta el séptimo día que nuevamente es irrigado. Esto se hace mas dinámico durante el verano que en el invierno, por el exceso de evaporación de agua del suelo, que arrastra las sales de los horizontes bajos hacia la superficie. Sin embargo, toda esta variabilidad en el tiempo, se lleva a cabo mayormente en el fondo del surco y en los niveles freáticos de riego. El lomo del surco (nivel no freático) permanece relativamente estable con niveles elevados de sal. En suelos fuertemente salinos, puede variar entre el fondo y el lomo del surco de 5 a $50 \mathrm{mmh}$.

En los suelos cultivados abandonados ya sin riego," la salinidad aumenta vertiginosamente desde la última irrigación que se hizo. La sal es arrastrada a estratos superiores y a medida que el suelo va perdiendo toda el agua disponible, se presentan cristalizaciones blancas de sal en toda la superficie de los suelos abandonados. Los niveles de sal son elevados en el fondo del surco y mayor es en el lomo del surco.

El agua de riego de origen subterráneo (pozos) que se utiliza es ligeramente salina, con una concentración de 1-3 $\mathrm{mmh} / \mathrm{cm}$, de acuerdo a su proximidad al mar. Al evaporarse el agua a riego, contribuye, aunque en poca escala, a la salinización del suelo. Por otra parte, el agua de riego de origen altoandino (lagunas) en el sur del Perú, contiene niveles moderados de boro, al evaporarse contribuye al incremento del boro tóxico en el suelo cultivado.

Los aporques durante el cultivo también producen un gran estrés a las plantas. Cada aporque arrastra gran cantidad de sales de la parte superior no freática de los surcos hacia la base de los tallos de la planta. Una vez irrigado, las sales son disueltas hacia la zona rodicular de la planta, produciendo quemaduras y clorosis en hojas y acelerando la senescencia de las plantas, como el caso de la papa.

El riego tecnificado, ya sea por goteo, aspersión, burbujeo o exudacion, tiene la ventaja de mantener el suelo con niveles bajos de salinidad en la zona radicular y freática (húmeda). Se observa una migración de las sales horizontalmente a pocos decímetros de la planta, durante todo el ciclo vegetativo del cultivo. Además, en el riego tecnificado no se requiere de aporques, o en el caso particular de la papa, muy pocos, evitando de esa manera grandes acumulaciones temporales de sales en la base de la planta. Sin embargo, una vez retiradas las mangueras o cintas exudantes, las sales migrarán nuevamente a la superficie del suelo. Un riego tecnificado mal conducido puede producir mucho estrés a la planta, debido a que la napa freática de este sistema es relativamente poca. Esto ocurre sobre todo en el riego por goteo y de riego por medio de cintas exudantes.

En general, la salinidad decrece a medida que se aleja del mar, hasta llegar a los niveles muy bajos no estresantes, a altitudes de 900-1000 m.s.n.m. Asimismo, la textura es francoarenosa a nivel del mar y va aumentando gradualmente en el contenido de arcilla. Esto involucra consecuentemente el incremento de la capacidad de campo del suelo (retención de agua en el suelo), disminuyendo el estres hídrico en los cultivos. Los experimentos conducidos desde el nivel del mar hasta 900-1000 m, nos indican que partiendo de altitudes entre 800-1000 msnm hasta el nivel del mar, la población de nemátodos ( $\mathrm{M}$. incógnita, $\mathrm{M}$. Javanica y $M$. arenaria), aumenta vertiginosamente, encontrándose alta presión poblacional en los suelos francoarenosos cerca del mar. Esto nos muestra la correlación existente entre la textura del suelo y el grado de presión poblacional del nemátodo del nudo de la raíz, plaga importante de muchos cultivos de la costa del Pacifico sur.

Por otra parte, los suelos árido-salinos de potencial agrícola son deficientes en fósforo y materia orgánica, por lo que es muy importante la incorporación de grandes cantidades de abono orgánico para mantener el equilibrio biológico del suelo, suministrando nutrientes a la planta y retener más agua en el suelo, además de reducir el daño causado por nemátodos, debido incremento en la microflora benéfica.

\section{III.PRODUCCIÓN DE PAPA CON SEMILLA BOTÁNICA (TPS)}

A principios de 1986, se inicia, dentro del proyecto, investigaciones conducentes a la adaptación de líneas o familias de semilla botánica de papa a las zonas áridas y salinas del sur del Perú. Se evaluaron 63 familias hibridas con un total de 17000 genotipos (seedlings). Los estreses de calor y salinidad dañaron a las plantas trasplantadas en estos suelos regados por gravedad o inundación parcial. No se seleccionó ninguna familia promisoria, sólo unos cuantos genotipos promisorios que sobrevivieron a las condiciones de estrés del desierto. Estos clones promisorios iniciales fueron multiplicados y sometidos a las pruebas serológicas de resistencia a virus y sometidos a evaluaciones en experimentos avanzados. 


\subsection{EVALUACIÓN DE HIBBRIDOS PROMISORIOS}

En 1991 se inicia otra estrategia y logística de evaluación de familias de TPS con progenies cuyos parentales habían sido previamente seleccionados en zonas áridas por su tolerancia a estreses abióticos. El experimento fue conducido en suelos áridos moderadamente salinos y utilizando riego por exudación. De diez familias evaluadas se logró seleccionar la familia promisoria C89.437 x ST.BULK, quien mostró mayor frecuencia de genotipos adaptados con caracteres agronómicos deseables, seguida de la familia TPS $387776.3 \times$ ST.BULK.

A principios de 1994 se evaluó un set de nuevos híbridos TPS superiores en zonas áridas, con suelos ligeramente salinos en diseños de blocks completamente randomizados con cuatro repeticiones. Las plántulas fueron cultivadas asociadamente con tubérculos-familias. Las familias TPS que más sobrevivieron a los estreses abióticos fueron SERRANA x LT.7 y LT.9 x TS.9. La variabilidad intra-familias permitió seleccionar 24 clones promisorios con potencial genético para una producción comercial. Sin embargo, las familias tubérculos, primera generación clonal de tuberculillos, mostraron mayor adaptación a los estreses, siendo los híbridos CHIQUITA x TS.4 y SERRANA x LT.7, los mejores rendidores en tubérculos, lográndose seleccionar 30 genotipos promisorios. En términos de rendimiento, ninguna de las familias de tubérculos o TPS superó al control COSTANERA. Las mismas diez familias TPS evaluadas para rendimiento de tuberculillos en substratos artificiales (invernadero), mostraron variabilidad enorme en el rendimiento, siendo los híbridos SERRANA x LT.7 y LT.9 x 104.12.LB, los de mayor rendimiento de tuberculillos por $\mathrm{m}^{2}$ (350 - 450 tuberculillos $/ \mathrm{m}^{2}$ ). La familia TPS. SERRANA x LT.7 parece ser la más adaptable a condiciones áridas, sin embargo, es necesario descartar experimentalmente alguna correlación positiva existente entre el efecto de estrés abiótico y la mayor producción de glycoalcaloides (solanina) en los tubérculos de papa.

Durante el verano de 1995 se evaluaron diez familias de tuberculillos provenientes de semilla botánica cultivadas en substratos de $1 \mathrm{~m}^{2}$. Los tuberculillos fueron sembrados en suelos áridos y

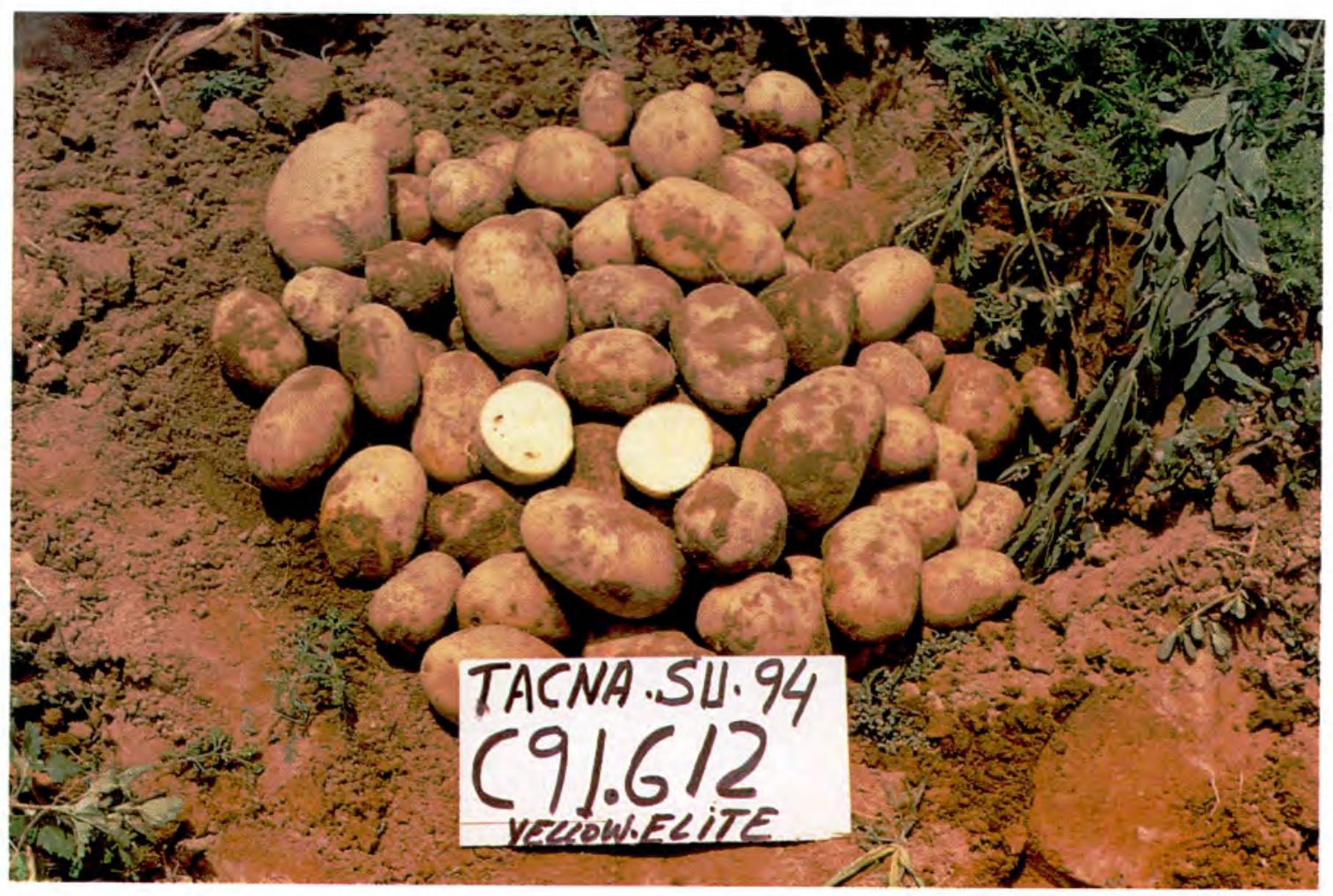

El clon élite SDC91.612 (BASADRE) presenta buena performancia agronóınica, tanto en rendimiento como en calidad, aun bajo condiciones de verano. 
ligeramente salinos. Las plantas mostraron un alto vigor (7 a 9) en el follaje, similar al vigor observado eñ los controles usados de tubérculos normales de las variedades Tacna y Costanera. Asimismo, todos las familias mostraron follaje normal, ausente de síntomas de enfermedades viróticas. La sobrevivencia de las plantas fue del $90 \%$ en contraposición de las plántulas de semilla botánica anteriormente evaluadas (cerca del $40 \%$ de sobrevivencia). La mayor performancia agronómica en la producción de tubérculos fue observada en la familia SERRANA x LT.7, con una alta uniformidad en color, forma y tamaño y con un rendimiento de $564 \mathrm{gr} /$ planta. En segundo lugar se registra el híbrido LT.9 $\times 104.12$ LB con un rendimiento de $528 \mathrm{gr} / \mathrm{planta}$, pero la calidad comercial de los tubérculos fue inferior. Ambos híbridos provienen de parentales tolerantes al calor $y$ resistentes a virus.

Los resultados de estos preliminares experimentos mostraron la posible alternativa del uso de la semilla botánica y tuberculillos de primera generación clonal en la producción comercial de papa en zonas áridas.

\subsection{TAMIZADO DE TPS EN SUELOS ÁRIDOS Y MUY SALINOS}

Durante el otoño de 1995 se evaluaron 15 familias TPS, cuyos progenitores fueron seleccionados en Tacna por su tolerancia a salinidad, sequía, calor, precocidad y resistencia a RKN. Se utilizó como control, la semilla de polinización libre de la variedad TIKAWASI. EI experimento se llevó a cabo en la localidad de Magollo, 400 msnm, bajo condiciones de aridez y suelos agrícolas fuertemente salinos, a fin de conocer la habilidad combinatoria para salinidad y sequía a los clones élites parentales. Se utilizaron 80 genotipos por familia, distribuidos en BCR con cuatro repeticiones (20 plantas por repetición). La conductividad eléctrica del terreno experimental fluctuó entre 5-18 mmhs y el contenido de boro de 3-9 ppm.

Las familias que mostraron mayor porcentaje de sobrevivencia a los 15 días de trasplante fueron SDC89.315 X ST.BULK, (72\%), SDC89.302 X SḊC89.315 (71\%) y SDC90.259 x ST.BULK $(65 \%)$. EI control TIKAWASI mostró muy baja sobrevivencia (14\%). La segunda evaluación de sobrevivencia realizada a 60 dias, después del transplante, muestra solamente mayor frecuencia de plantas sobrevivientes con vigor de 1 a 3 , (no se registró mayor vigor) en las familias SDC91.934 x SDC89.315 (36\%); SDC90.259 x ST.BULK (30\%) y SDC89.308 X ST.BULK (27\%).

Sin embargo, no hubo una fuerte correlación en algunas familias en la frecuencia de supervivencia y la producción de tubérculos de calidad, habiendo tenido mayor producción de tuberculillos de buena calidad las siguientes familias : SDC90.259 x ST.BULK, SDC91.934 x SDC89.315 x ST.BULK y SDC91.902 $x$ SDC89.315.

El tamizado de estas 15 familias sugiere que los clones élites, utilizados como parentales SDC89.315, SDC90.259 y SDC90.260, tienen una gran habilidad combinatoria para resistencia a suelos muy salinos, debido a que proporcionan en la primera generación mayor frecuencia de híbridos o genotipos resistentes a salinidad. Por consiguiente, las mejores combinaciones para suelos muy salinos serían : SDC90.259 x ST.BULK , SDC91.934 x SDC89.315 y SDC89.315 x ST.BULK.

\subsection{EVALUACIÓN DE HÍBRIDOS SUPERIORES}

En otoño de 1995 se utilizó una nueva e innovadora estrategia de producción de papa a partir de semilla botánica TPS. Se seleccionaron previamente un grupo de diez híbridos superiores cuyos progenitores se presumía que tenían una gran habilidad combinatoria para atributos agronómicos y cuyas semillas híbridas fueron seleccionadas por su alta calidad de embriones. El potencial genético de estos híbridos fue puesto a prueba en suelos áridos y ligeramente salinos, bajo condiciones de baja temperatura y fotoperiodo corto, en Pachía, Tacna (1000 msnm). El material fue trasplantado de almácigo al campo y el follaje fue cortado a los 80 días a fin de determinar también su precocidad. Se evaluó la supervivencia y el vigor del follaje a los 60 días del trasplante. Los resultados obtenidos fueron sorprendentes:

a) Se observó una alta frecuencia de sobrevivencia de las plantas trasplantadas.

b) Se detectó un incremento conspicuo en el vigor de las plantas en las familias. En algunas familias y repeticiones se observó un grado de vigor 9 .

c) Se observó una mayor frecuencia de genotipos 
ideales para ser usados, ya sea como clones promisorios o como futuros parentales para generar nuevas familias híbridas en zonas áridas, con un rendimiento de 900-1000 gr/ planta y excelente calidad de tubérculos y su extraordinaria precocidad.

Las familias superiores que más destacaron por su performancia general agronómica fueron: MF-I X TS.5 con $67.3 \%$ de supervivencia y vigor general promedio de $7.6, \mathrm{MF}-\| \times \mathrm{XY} .13$, con $83.5 \%$ de supervivencia y vigor general promedio de 7.5 , MF-II x TS.13, con $46.4 \%$ de supervivencia y vigor general promedio de 7.4. En total, de estos tres híbridos superiores se seleccionaron 57 genotipos por la arquitectura ideal de la planta. Los 57 genotipos o clones iniciales de papa fueron evaluados bajo condiciones de baja temperatura y días largos de verano en la sierra en Huancayo (3300 msnm). Sin embargo, durante la cosecha, que se realizó en Huancayo, a los 90 días, se observó una alta frecuencia de clones (51) desadaptados a las condiciones de sierra y fotoperiodo largo. La mayoría mostró tubérculos pequeños y estolones indeseables, por lo que fueron descartados.

Dos familias de tubérculos provenientes de semilla botánica (TF-TPS), MF-I x KATAHDIN y MF-I x TS.3, seleccionadas bajo condiciones de baja temperatura y días cortos (invierno), fueron evaluadas en campo de agricultor durante fotoperiodo largo y altas temperaturas (primaveraverano). Ambos híbridos mostraron un gran vigor en el follaje superior a la variedad DESIREE, utilizada como control, así como ausencia de síntomas de enfermedades viróticas. Sin embargo, la tuberización y calidad de los tubérculos fue alta en el híbrido MF-I x KATAHDIN y superior a Desiree, habiéndose seleccionado 27 clones promisorios de un total de 168 evaluados. Por el contrario, la tuberización fue muy escasa y muy inferior a Desiree en el híbrido MF-I X TS.3, pues la mayoría de los 192 clones evaluados, presentaron estolones largos y tubérculos pequeños.

En la zona semiárida altoandina de Tacna, (Tarata) a $3100 \mathrm{msnm}$, se estableció un experimento de primavera-verano con dos poblaciones de papa de TF-TPS, seleccionadas en suelos no estresados en La Molina, Lima. El vigor del follaje fue moderado en ambos híbridos: FK.69 x CEW.69, SERRANA $\times$ TS.9.
Durante la cosecha se observó una gran diferencia de producción de tubérculos en ambos híbridos. El híbrido CFK.69 X CEW 69.1 presentó mayor performancia agronómica, habiendo seleccionado 20 clones de un total de 150 sembrados. Del híbrido SERRANA x TS.9 de muy bajo rendimiento, solamente se pudieron seleccionar 7 clones de un total de 145 plantas o genotipos sembrados.

Con la finalidad de evaluar las alternativas de la producción comercial de papa en zonas altoandinas, se diseñó un experimento para determinar la performancia agronómica de 61 familias híbridas de TPS. Estos híbridos combinan alta precocidad, resistencia a virus y a la rancha en la papa (Phytophthora infestans). Debido a la poca emergencia de plántulas en las bandejas de germinación, nueve familias fueron descartadas. La germinación y emergencia de las plántulas hasta llegar al tamaño de transplante $( \pm 10 \mathrm{~cm}$.) fue de 50 días, es decir, 20 dias más que en la costa, debido a las bajas temperaturas. El período de crecimiento fue de 90 dias (20 enero-20 abril). Se observó un vigor moderado en el follaje de las familias y una gran variabilidad intra e interfamilias para la susceptibilidad al ataque del tizón temprano de la papa: Alternaria solani. Asimismo, a los 70 días después del transplante hubo incidencia de heladas tempranas que afectaron a un $30-40 \%$ en las plantas, acelerando su senescencia. De una población total de 5200 genotipos evaluados, se marcaron y seleccionaron 193 clones o genotipos promisorios. Las siete familias que tuvieron una performancia agronómica moderada (vigor 5-7) frente a las demás fueron:

1. TS. $6^{*} \times 104.12 . B^{* *}$

2. TS. $11 \times 104.12 . \mathrm{LB}$

3. TS. $14 \times 104.12$. LB

4. LT. $8 \times R .128 .6$

5. ATZIMBA $\times$ R.128.6

6. MF-II $\times$ 104.12.LB

7. LT. $8 \times 104.12 . \mathrm{LB}$

* Los progenitores femeninos aportan mayormente genes de gran precocidad y tolerancia al calor.

** Los progenitores masculinos, como 104.12.LB, aportan genes de resistencia a la rancha de papa, Phytophthora infestans.

Estos resultados nos indican que la siembra y transplante de TPS en la zona altoandina, debería hacerse más tempranamente y en dos 
campañas agrícolas, es decir, octubre-diciembre y enero-marzo, con el mismo grupo de familias TPS.

Bajo condiciones de baja temperatura y fotoperiodo corto y en suelos no estresados en $\mathrm{La}$ Molina - Lima, se evaluaron 53 familias TPS para determinar su rendimiento a los 90 días. En la cosecha se seleccionaron únicamente las familias de mejor rendimiento y uniformidad en tubérculos. Estas tres familias seleccionadas, (TF-TPS); TS.9 x TPS. 67, TS. 14 x TPS. 67 y TS. 9 x XY. 4 fueron sembradas en las zonas áridas y suelos semisalinos de Tacna, Pachia, en un diseño experimental junto con el control vr. Desiree. La mayor performancia agronómica, bajo condiciones de otoño (baja temperatura, fotoperiodo corto), fue observada en el híbrido TS.9xXY.4 con alta precocidad, vigor y rendimiento.

Nuevos híbridos superiores de TPS y TF-TPS están siendo evaluados sistemáticamente en diferentes condiciones edáficas y bajo condiciones de días cortos, baja y alta temperatura. Los resultados de estos experimentos servirán para una utilización óptima de estas familias TPS en las zonas áridas del Tercer Mundo.

\subsection{PROSPECCIÓN FUTURA DE TPS EN ZONAS ÁRIDO SALINAS}

Los resultados promisorios de estos experimentos muestran la factibilidad de la producción de papa comercial para consumo y de semilla tubérculo de papa a partir de TPS libre de enfermedades viróticas en zonas áridas y suelos pøco salinos. Sin embargo, es necesario ampliar la base genética de la TPS para tolerancia a estreses abióticos en zonas áridas y para fotoperíodos cortos y largos, así como altas y bajas temperaturas. Asimismo, es necesario identificar familias hí bridas de TPS, insensibles a diferencias de fotoperiodos. En este sentido se ha programado la utilización de familias TPS, cuyos parentales, en lo posible masculino o femenino, sean muy precoces y tolerantes al calor, salinidad y sequía. En la actualidad, se está evaluando 40 grupos de familias avanzadas de TPS bajo condiciones de invierno y primavera. Asimismo, se viene logrando clones promisorios que pueden ser usados como progenitores en la generación de familias híbridas de TPS para zonas áridas y salinas.

\section{IV.GENERACIÓN DE CLONES Y PROGENITORES SUPERIORES DE PAPA PARA LAS CUATRO ESTACIONES DEL AÑO}

De un total de 30 clones avanzados de papa, evaluados en condiciones semiáridas de la sierra surperuana, durante la primavera de 1994 , solamente se logro seleccionar el clon avanzado SDC92.019 con un período de crecimiento de 90 días y un rendimiento promedio de $850 \mathrm{~g} / \mathrm{planta}$. Los agricultores de la zona de Tarata, que estuvieron presentes en la cosecha, mostraron su deseo de nominar a este clon como "Tarateña".

En enero de 1994 se establece en Tarata (3100 msnm) un experimento avanzado con 16 clones élites precoces y tolerantes al calor y cuatro controles locales. Se logró la identificación de cinco clones adaptados a las condiciones de la sierra peruana (SDC89.262, SDC89.315, SDC92.132, SDC92.145, SDC91.906), habiendo sido superado solamente por la variedad $\mathrm{CICA}$. El descubrimiento de estos clones superprecoces para las condiciones de sierra peruana, permitiría el cultivo de papa en primavera y en verano, asimismo, permitiría el establecimiento de un sistema de producción de semilla certificada para su cultivo en la costa.

Durante el verano de 1995-1996 se realizaron dos experimentos simultáneos en las zonas agroecológicas semiáridas de Ticaco (3300 msnm) y Tarata (3100 msnm), para determinar la performancia de 37 clones élites, incluidos los clones seleccionadas anteriormente en otras zonas. La cosecha realizada a los 90 días de la siembra mostró el extraordinario rendimiento y calidad de tubérculos del clon SDC 91.612 (BASADRE), junto con los seis clones élites mencionados anteriormente. Estos siete clones mostraron buena y alta calidad para procesamiento industrial.

En enero de 1995 se evaluaron 34 clones promisorios, bajo condiciones de altas temperaturas de verano en suelos áridos, medianamente salinos. Estos clones fueron seleccionados previamente, de un grupo de 240 clones en suelos muy salinos bajo condiciones de invierno y por su calidad para procesamiento industrial y resistencia a los virus PVX y PVY. Durante la cosecha se identificó como el mejor, el clon C92.085, proveniente de en cruzamiento de GRANOLA por XY.20 con un rendimiento comercial de $923 \mathrm{~g} /$ planta y de un excelente valor comercial, habiendo superado aventajadamente a los cuatro clones utilizados. 
Se realizó la evaluación de 11 clones precoces y resistentes a estreses abióticos bajo condiciones de verano - otoño en suelos ligeramente salinos, intercalados con familias TPS. La semilla tubérculo utilizada fue de cuarta generación clonal de Tacna. El experimento fue conducido en Pachía a 1000 m.s.n.m. El follaje fue cortado a los 90 días después de la siembra. Durante la cosecha se determinó la gran performancia agronómica de los clones élites SDC91.640, SDC89.315, SDC91.906 y SDC91.612, los cuales superaron en rendimiento a los tres controles usados.

Se llevó a cabo un experimento en chacra de agricultor en la zona de Pocollay a 700 m.s.n.m. en suelos áridos ligeramente salinos, bajo condiciones de invierno - primavera - 1994. Se utilizaron 17 clones precoces mejorados y tres controles. La cosecha y evaluación de rendimiento y calidad de los tubérculos fue realizada a los 100 días después de la siembra. Seis clones mejorados SDC89.315, SDC89.262, SDC92.132, SDC92.640, SDC92.018 y SDC89.311 mostraron una extraordinaria precocidad y rendimiento con mas de mil gramos de tubérculos por planta, habiendo superado a los tres controles utilizados (DESIREE, REVOLUCION y PERUANITA) y aun a las variedades de alta calidad industrial Tacna y Costanera.

En la misma localidad de Pocollay se evaluaron once clones mejorados bajo condiciones de otoño invierno 1995. Se utilizaron las variedades DESIREE y REVOLUCION como controles. Se determinó mayor rendimiento en los clones SDC91.514 (944 g/p), SDC89.311 (889 g/p). Sin embargo, los clones SDC89.019 y la variedad Tacna mostraron rendimientos moderados pero con tubØrculos de alta calidad en grado nueve.

Los resultados de más de 60 experimentos conducidos en las cuatro estaciones del año en las zonas áridas de Tacna, Moquegua y Arequipa, nos indican diferencias en la performancia agronómica general y en el rendimiento y calidad de tubérculos en particular de los clones mejorados por efecto del fotoperiodo y la temperatura. Esto sucede especialmente a 18 grados de latitud sur. Sin embargo, se ha logrado determinar ocho clones mejorados en las zonas áridas como SDC91.640 (UNTACIP) y SDC91.612 (BASADRE), que presentan una alta performancia agronómica en el tiempo y espacio, y son insensibles a diferencias de fotoperiodo y temperatura.

A la fecha se cuenta con 35 clones superiores de papa, adaptados a las condiciones áridas y salinas de la costa peruana, superprecoces y tolerantes al calor. La gran mayoría de los clones tienen alta calidad industrial para la elaboración de ojuelas, papa frita, papa semifrita congelada, almidón y harina. De este caudal de clones élites generados por este proyecto, siete presentan adaptación a condiciones semiáridas de la sierra (3100 m.s.n.m.). Asimismo, ocho de estos clones han sido ya introducidos al sistema de cultivo in vitro y a pruebas serológicas (ELISA) para la detección y eliminación de virus. Esto favorecerá enormemente la producción de plántulas y tuberculillos libres de patógenos para la distribución nacional e internacional. (Tabla PO.01).

\section{GENERACIÓN DE CLONES Y PROGENITORES SUPERIORES DE CAMOTE PARA LAS CUATRO ESTACIONES DEL AÑO}

Dentro de la estrategia de mejoramiento genético de camote se considera también la selección de clones adaptados a las condiciones de verano, otoño, invierno y primavera, a fin de proveer en el futuro materia prima permanente a la agroindustria. Los avances en este campo han sido grandes, pues, se tienen más de 300 clones superiores de verano, de invierno y tolerantes a ambas estaciones, con rendimientos comerciales aceptables y resistencia de campo a RKN.

Durante el verano de 1995, se seleccionaron 220 clones promisorios provenientes de 24 familias de policross (1820 seedlings). De esta población promisoria se seleccionaron bajo condiciones de invierno 17 clones avanzados, con un rendimiento superior a $700 \mathrm{~g} /$ planta en un período de crecimiento de 120 días. Estos clones están siendo multiplicados para experimentos avanzados. (Tabla SP.1).

Con la finalidad de diseminar y multiplicar las variedades liberadas en Tacna en el ámbito nacional, se estableció un experimento en Moquegua, La Villa, $1300 \mathrm{msnm}$. Las 10 variedades que se mencionan en la tabla SP.2, han demostrado buen rendimiento y adaptación a las condiciones del valle de Moquegua. Sin embargo, las variedades que más han destacado han sido Ite, Caplina, Yarada y Comensal, en orden de rendimiento.

Con la finalidad de evaluar la adaptación a sequía de clones resistentes a salinidad, se llevó a cabo un experimento con 19 clones élites y un control en zonas áridas y agrícolamente muy salinas. Durante el cultivo experimental, tres repeticiones se hicieron con riego normal y nueve repeticiones se sometieron 
a 30 dias de sequía. Los resultados han sido sorprendentes: seis clones superiores han mostrado tener doble juego de genes, es decir, para resistencia a salinidad y para resistencia a sequía, estos son: TN91.012, TN89.316, LM89.119, ST87.117, TN88.105 y LM89.125. (Tabla SP.3)

De un total de 450 clones mejorados de camote, tolerantes a estreses abióticos, precoces y resistentes al nemátodo del nudo de la raíz, se han seleccionado 10 clones por su gran potencial agronómico y calidad para procesamiento industrial. Ocho de estos clones han sido liberados para la agricultura nacional por la Universidad Nacional Jorge Basadre Grohmann de Tacna y el Centro Internacional de la Papa. Estos 10 clones mejorados han sido introducidos al sistema in vitro y se encuentran almacenados en el Banco de Germoplasma in vitro del Centro Internacional de la Papa, encontrándose listos para su distribución nacional e internacional de plántulas libres de patógenos. En la segunda columna de la tabla SP.2 se menciona el código internacional para realizar los pedidos con seis meses de anticipación, esto para permitir su previa micropropagación y envío posterior.

Dentro de la logística del mejoramiento genético del camote para zonas áridas y salinas de la costa árida, también se considera la generación de clones superiores no convencionales con atributos especiales. En este sentido, durante el invierno de 1995 se ha evaluado más de 800 clones promisorios, previamente seleccionados en verano, por su alto contenido de caróteno y de colorante anthocianina. Asimismo, se han seleccionado clones resistentes a salinidad y nemátodos, los cuales fueron previamente seleccionados por su tolerancia a toxicidad de aluminio y suelos ácidos del trópico bajo de la selva peruana.

Los resultados de más de 30 experimentos conducidos en estaciones experimentales y chacras de agricultores durante 1995 y 1996 en la costa surperuana, confirman el potencial de adaptación a diferentes fotoperíodos y temperaturas de 12 clones élites de camote, incluidas las seis variedades liberadas. Estos clones mejorados se caracterizan también por su gran precocidad y mayor porcentaje de materia seca para la agroindustria.

\section{PRESIÓN DE SELECCIÓN PARA TOLERANCIA A OTROS ESTRESES ABIÓTICOS}

En un estado avanzado del presente proyecto, cuando se determinó una considerable ganancia genética, se sometió a la gran mayoría de los clones mejorados de papa y camote a evaluaciones y tamizados para tolerancia a los estreses de toxicidad de boro y sequía.

\subsection{TAMIZADO PARA RESISTENCIA A TOXICIDAD DE BORO}

Los niveles elevados de boro en las zonas áridas de la costa peruana, como el caso de los valles costeros de Sama y Locumba, donde alcanzan a niveles de 10 a 14 ppm., producen al igual que el estrés de salinidad, un efecto de crecimiento retardado, clorosis y quemadura de hojas en plantas de papa y camote. Asimismo, el efecto nocivo del boro tóxico se presenta en clones avanzados, tolerantes a salinidad y sequía. Es por eso que el ensamblaje de estos tres atributos de resistencia a sal, sequia, toxicidad y boro es necesario para la adaptación integral de los clones liberados a zonas marginales desérticas del Tercer Mundo.

En los últimos tres años se han realizado evaluaciones de 60 clones promisorios, resistentes a salinidad en suelos salinos, pero con niveles tóxicos de boro (de 8 a $12 \mathrm{ppm}$.) en las localidades representativas de Sama, Locumba e Ite. Gracias a experimentos con diseños BCR, se ha logrado identificar tres clones de camote que ofrecen rendimientos comerciales aceptables en este tipo de suelos. Estos clones son: LM89.125, liberado como variedad COSTANERO, luego el clon CC89.021, nominado como Ite y luego el clon TN90.178. No se ha encontrado una correlación negativa entre: a mayor daño del follaje ocasionado por boro un menor rendimiento de raíz reservante. Así por ejemplo, se tiene el caso del clon TN89.231, que mostró un alto vigor en el follaje en grado 9 y un mínimo daño producido por la toxicidad de boro, sin embargo, su rendimiento de raíces reservantes fue muy bajo. Los clones avanzados de papa, tolerantes a salinidad y sequía, seleccionados para las zonas áridas y salinas, presentan una moderada tolerancia a niveles tóxicos de boro que fluctúa entre 4 y 6 ppm.

\subsection{TAMIZADO PARA RESISTENCIA A SEQUIAA}

Durante el verano y otoño de 1994 se evaluaron un total de 20 clones avanzados de camote, tolerantes a salinidad, bajo condiciones de suelos salinos francoarenosos. El experimento fue conducido por un periodo vegetativo de 120 dias y fue dividido en dos parcelas experimentales: La primera parcela experimental fue conducida con tres repeticiones y bajo riego normal , cada semana, durante todo el ciclo vegetativo de las plantas. La segunda parcela 
experimental fue conducida con estrés temporal de sequía durante treinta días (sin riego) y subdividida en tres parcelas, cada una con tres repeticiones. Las plantas fueron sometidas al estres de sequía durante treinta días. En la primera subparcela, el estrés de sequía fue a los treinta días después de la siembra, en el segundo a los sesenta días, y en el tercero a los noventa dias después de la siembra. Los parámetros utilizados para determinar el grado de resistencia a sequía fueron el rendimiento de raíces reservantes por planta, la calidad comercial del camote, y el vigor del follaje.

En general, los clones mostraron más sensibilidad al estrés de sequía producida en la última etapa de crecimiento, que en la primera y segunda etapa. Los clones tolerantes a salinidad: ST87.117, TN91.012, LM89.119, LM89.125, TN88.125 y TN89.316, mostraron la más alta performancia agronómica bajo los tres diferentes estreses de sequía. Todos los clones evaluados, con excepción de ST87.030 y SR89.519, mostraron buenos rendimientos bajos condiciones de riego normal. El promedio de conductibilidad eléctrica para las cuatro subparcelas en el lomo de los surcos fue de 13.7 mmhs. Se observó que el estrés de sequía incrementa la salinidad en las parcelas sin riego, factor que hizo un poco más complicada la interpretación de los resultados. El vigor del follaje disminuyó, la clorosis y defoliacion se incrementó, a medida que se incrementaba el número de días de sequía en los clones susceptibles a sequía. En general, el follaje verde y vigoroso mostró alta correlación positiva con el alto rendimiento y la resistencia a sequía.

Comparando los resultados de los dos experiemntos, podemos ver que el estrés de sequía reduce la produccion total de materia seca, el rendimiento de raíces reservantes por planta y la biomasa del follaje. Sin embargo, se incrementa el porcentaje de materia seca por cada raíz reservante. El mejor rendimiento obtenido en los clones ST87.117, TN91,012 y LM89.119 se debió principalmente al alto índice de cosecha de estos clones y a su gran resistencia a salinidad bajo condiciones de sequia. Sin embargo, el más alto rendimiento registrado por los clones LM89.119 y TN89.316, bajo el estrés de sequía en el último periodo de crecimiento, aun superando el rendimiento de riego normal, plantea una nueva hipótesis

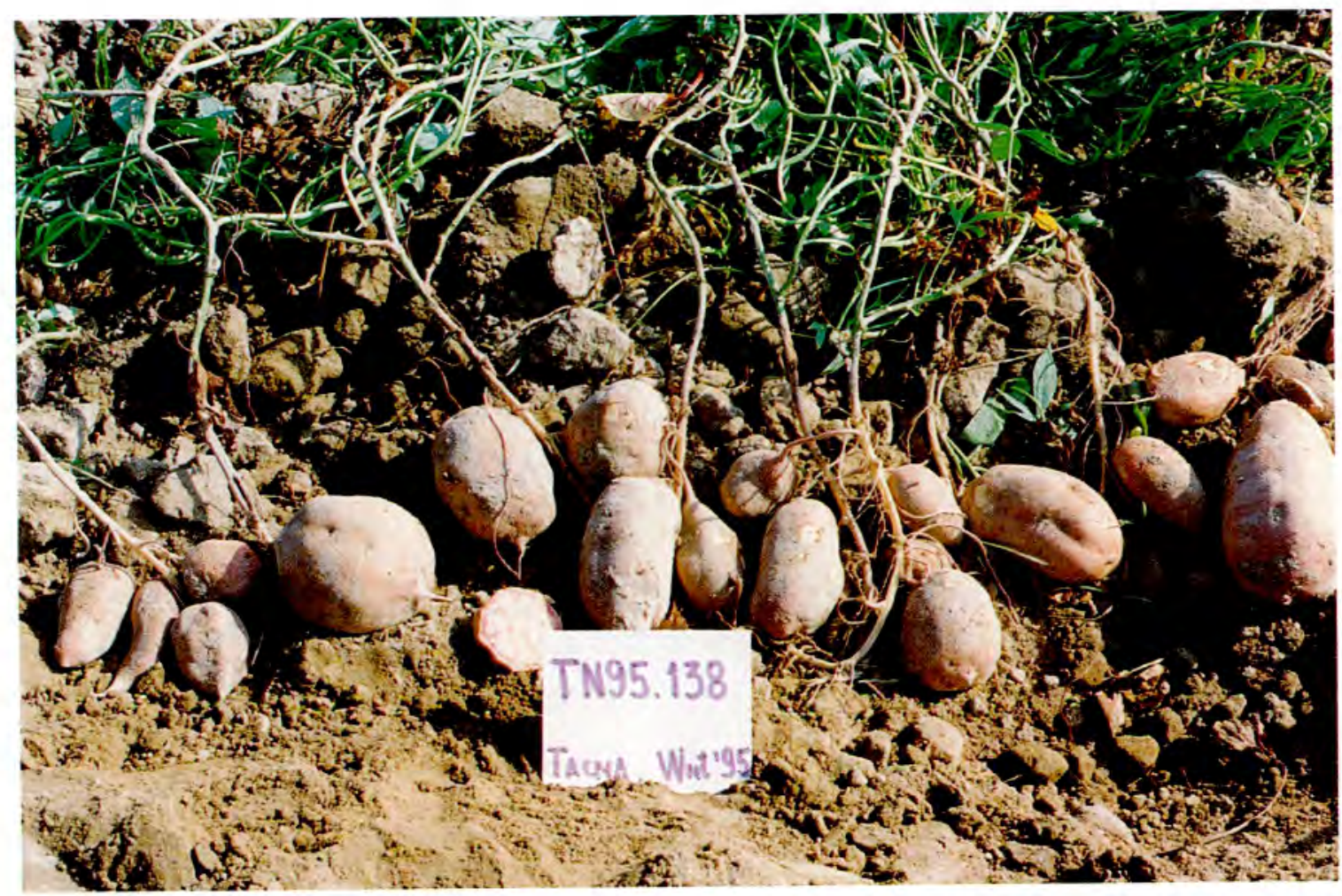

El clon promisorio TN9595.138 presenta altos rendimientos, aun bajo condiciones de invierno, como en La Yarada, en un período vegetativo de 120 días. 
controvertida, que tenía que ser resuelta en otro experimento, pero en suelos menos salinos.

Durante el otoño de 1995 se llevó a cabo un experimento con las ocho variedades mejoradas y liberadas de camote y el cultivar local Morado de Los Palos, y un clon promisorio de doble propósito (Gran Forrajero). El experiemento fue conducido en suelos franco arenosos y con moderada salinidad y bajo condiciones de baja temperatura, a fin de evitar grandes fluctuaciones del nivel de salinidad edáfica. El experimento se dividió en dos parcelas, la primera con cuatro repeticiones y riego normal. La segunda parcela fue dividida en cinco subparcelas, cada una con cuatro repeticiones y bajo cinco diferentes tipos de estrés de sequía. La performancia agronómica general fue determinada por el rendimiento de la raíz reservante por planta y por la calidad cormercial del camote producido. La mayor performancia agrónomica fue observada en los mismos clones o variedades anteriormente registradas en orden de rendimiento y calidad comercial: UNTACIP (TN91.012); SALYBORO (TN88.085); COSTANERO (LM89.119) y YARADA(TN89.316). Se observó que el rendimiento, calidad y contenido de materia seca, se incrementaba moderadamente a medida que las plantas eran sometidas a riego restringido cinco a seis semanas, antes de la cosecha en un periodo vegetativo de 120 días. (Tabla SP.2)

Desde el otoño de 1995 hasta el invierno de 1996 , se ha conducido trece experimentos de camote, en los cuales la irrigación normal se ha hecho a las plantas solamente hasta los 70 - 90 días después de la siembra, cortando el riego hasta la cosecha. Asimismo, se ha sometido a un población de 1300 clones promisorios a riegos restringidos, a fin de tener material genético avanzado, tolerante a sequía. Esta presión de selección ha permitido obtener hasta la fecha cerca de cincuenta clones avanzados con doble resistencia: a salinidad y sequía.

Los clones avanzados de papa, tolerantes a salinidad, también han sido sometidos a estreses moderados de sequía, riego restringido, como parte de la estrategia para la adaptación general a zonas áridas, donde el recurso agua es escaso y restringido. Durante la primavera y verano de 1995, se condujo un experiemento con 14 clones de papa, bajo condiciones de fotoperiodo largo y alta temperatura y en suelos ligeramente salinos, franco-areno-limoso. El experiemnto fue dividido en dos parcelas, una con riego normal, cada ocho días, y la otra con estreses de sequía a los 60 días, después de la siembra, con un periodo vegetativo de 90 días. La tolerancia a sequía fue determinada con el rendimiento y la calidad de los tubérculos por planta, así como en la calidad industrial de hojuelas fritas. Los clones de buena performancia agronómica y calidad industrial bajo condiciones de estrés de sequia fueron: SCDC91.628, SDC92.019, SDC 92.145 (DESERTICA) y SDC91.612 (BASADRE). En general, se observó un incremento de la calidad industrial de los clones con el riego restringido. La variedad TOMASA, usada como control, ocupó el último lugar del rankin. Siete clones superaron en rendimiento a la variedad DESIREE bajo riego normal, sin embargo, DESIREE ocupó el tercer lugar en tolerancia al estrés de sequía y con buena calidad para procesamiento industrial.

\section{BASES DE LA ESTRATEGIA GENÉTICA Y EL AVANCE DE SELECCIÓN}

La principal estrategia en el mejoramiento para tolerancia a salinidad y otros estreses relacionados a zonas árido-salinas es el desarrollo de poblaciones por un sistema cíclico de selección recurrente que permita llegar a las siguientes metas:

1. Mantener una amplia base genética para resistencia a estreses abióticos en papa y camote.

2. Incrementar los genes que controlan la precocidad y tolerancia al calor en papa.

3. Incrementar la frecuencia de genes que gobiernan la precocidad y tolerancia a bajas temperaturas (invierno costero) en camote.

4. Seleccionar familias TPS y clones superiores, adaptados a fotoperiodos cortos, largos e insensibles al fotoperiodo.

5. Incrementar la frecuencia de genes para la resistencia a sequía en papa y camote.

6. Buscar la combinación favorable de caracteres agronómicos deseables, con la calidad industrial en los nuevos clones híbridos seleccionados.

7. Buscar la incorporación de genes de resistencia a plagas y enfermedades predominantes en zonas áridas, en el germoplasma mejorado de papa y camote.

8. Generar progenitores o parentales de buena habilidad combinatoria para tolerancia a estreses abioticos.

Por otra parte, el rendimiento final de una planta tuberífera, como el caso de la papa y el camote, está determinado por la suma de la acción de un caudal de genes agrupados en tres categorias: 
a) Los genes de rendimiento per se

b) Los genes de adaptación.

c) Los genes de resistencia a plagas y enfermedades

Basado en este principio, el presente proyecto se ha concentrado en el grupo de genes de adaptación mayormente poligénicos, que son los que determinan la adaptación de genotipos a los estreses abióticos, como la salinidad, calor, baja temperatura, sequia y toxicidad de boro y aun la precocidad. En este sentido, la generación y desarrollo de un clon élite con gran potencial de rendimiento es el resultado principalmente de una combinación favorable de los genes aditivos y epistáticos.

Para el desarrollo de nuevas poblaciones se ha venido utilizando policruzas (camote) y cruzamientos recíprocos dirigidos (papas), entre plantas de progenitores debidamente seleccionados mediante pruebas de progenie. Las pruebas de progenie son de gran valor en la selección de progenitores, ya que no es suficiente que un clon élite o superior, candidato a progenitor, muestre excelentes atributos fenotípicos, sino que es más importante que una proporción significativa de la descendencia de este clon élite muestre los atributos agronómicos deseables, heredados de sus progenitores. Contando con este tipo de materiales parentales se puede lograr un progreso sostenido dentro de la selección recurrente. En este sentido, se estableció la generación y evaluación correspondiente de familias dialélicas para resistencia a estreses abióticos, así como parentales masculinos y femeninos con buena habilidad combinatoria para resistencia a sequía y salinidad.

En el caso de la papa $(2 n=4 x=48=A A A A)$ y el camote $(2 n=6 x=90=B B B B B B)$, son cultivos de naturaleza alógama, autopoliploides con un sistema de herencia tetrasomica y hexasómica, respectivamente. Los resultados de mejoramiento genético, mediante la aplicación de diseños genéticos madre-progenie han sido muy favorables. La información genética disponible sobre papa y camote indica que el método de selección recurrente, con los diseños genéticos I y II, es la ruta más adecuada para seguir en el mejoramiento para tolerancia o resistencia de estreses abióticos. Este método permite aprovechar al máximo la acción genética aditiva, de dominancia y epistática, que en suma determinan el rendimiento final de la planta tuberífera.

\subsection{MÉTODO DE POLYCRUZAS}

Para el desarrollo de nuevas poblaciones de camote, se ha venido utilizando un sistema de policruzamientos y últimamente cruzamientos recíprocos dirigidos entre plantas de progenitores debidamente seleccionados mediante pruebas de progenie. Estos diseños genéticos permiten la expresión de los genes de dominancia, aditiva y epistática en la expresión de los caracteres poligénicos agronómicos deseables de camote.

En este diseño se aprovecha también la autoincompatibilidad esporofítica de los clones superiores de camote seleccionados como progenitores, gracias a que reúnen los siguientes caracteres:

1) Buenos atributos agronómicos y resistencia a RKN.

2) Alto grado de floración.

3) Gran capacidad de producción de cápsulas y semillas viables.

Las policruzas se diseñan con 20 a 40 clones progenitores tolerantes a estreses abióticos en el campo, en cuadrados latinos y bajo riego restringido para favorecer la mayor floración (Tabla SP.1). En el campo, las abejas hacen el trabajo de polinización cruzada con todas las combinaciones posibles.

Si se utiliza 30 clones parentales resistentes a sequía y salinidad, se obtendrá semilla de 30 clases. Cada grupo de semillas cosechadas de un progenitor será el resultado de la hibridación del clon femenino, donde se cosecha la semilla y la mezcla del polen de los otros 29 progenitores masculinos que aportaron el polen a través de las abejas. No habrá familias autopolinizadas, debido a naturaleza de autoincompatibilidad de cada progenitor. En total, desde el punto de vista teórico, se realizan 870 combinaciones posibles, donde los grupos de semilla cosechada son híbridos, pero cada grupo o población está conformado solamente por hermanos de madre.

Los nuevos grupos de semilla son sembrados y germinados. Las plántulas son transplantadas al campo en dos grupos. Un grupo de plántulas es utilizada para el tamizado directo a suelos salinos con riego restringido, el cual conlleva a la identificación de clones promisorios. El otro grupo de plántulas o genotipos es utilizado en un experimento madre-progenie. Generalmente se utiliza 100 plántulas o genotipos por híbrido, divididos en cuatro repeticiones, junto con otras 100 plántulas del mismo clon parental femenino. Siendo las 100 plántulas transplantadas, 
hermanas de madre, se trata de establecer el potencial hereditario de cada clon parental femenino en particular y de toda la población de progenitores masculinos en general, en el campo experimental.

La frecuencia de genotipos con caracteres agronómicos deseables, bajo condiciones de estrés abiótico de la progenie, en relación a los progenitores, nos dará un valor de la heredabilidad para cada caracter agronómico. A principios del proyecto, las primeras policruzas y experimentos madre-progenie mostraron una baja heredabilidad para tolerancia a salinidad y sequía. La gran segregación dentro de cada familia permitió solamente seleccionar clones promisorios. Durante los últimos cuatro años se ha logrado una mayor ganancia genética, gracias a la utilización de progenitores híbridos de buena habilidad combinatoria para caracteres agronómicos de origen asiático y progenitores resistentes a estreses abióticos originados en el presente proyecto.

\subsection{AVANCE RÁPIDO DE SELECCIÓN PARA ALTA PRECOCIDAD EN CAMOTE}

Desde el principio, en el proyecto de mejoramiento genético del camote, se estableció la estrategia de incorporar mayor precocidad a los clones selectos de camote. Los primeros experimentos con el germoplasma nativo o primitivo de camote demostraron que la gran mayoría de las variedades nativas o primitivas del camote eran tardías, con un periodo vegetativo de cinco a seis meses. Las primeras poblaciones híbridas, generadas en el proyecto, se sometieron a una presión de selección de 120 días de periodo vegetativo. Durante 10 años de hibridación y selección, todos los genotipos o clones promisorios han sido cosechados a los cuatro meses después de la siembra. En una etapa más avanzada se sometió a los cultivos experimentales a riegos restringidos, generalmente a partir de los 70 días después de la siembra.

A fines de 1995 se tenía 650 clones avanzados de camote, tolerantes a estreses abióticos, incluida la tolerancia a las bajas temperaturas de invierno. De esta población se seleccionaron 120 clones avanzados de mayor potencial agronómico y adaptación a las condiciones desérticas para ser sometidos a una alta presión de selección para precocidad y reducir el período vegetativo comercial del camote de 120 a 90 días.

Durante las primeras semanas el riego aplicado fue normal, a fin de favorecer el establecimiento de los esquejes plantados. A partir de los 60 días, después de la siembra, el experimento fue sometido a un estrés hídrico con riego restringido. La evaluación de la performancia agronómica durante la cosecha realizada a los 90 días, mostró un enorme rango de variabilidad genética relacionada con el rendimiento de raíces reservantes y su valor comercial. La escala de evaluación utilizada fue 1 a $9(1,3,5,7,9)$. El valor 1 correspondió a un valor comercial muy bajo, muy poca tuberizacion y el valor 9 a valor comercial alto, abundante y uniforme tuberizacion. Todos los clones avanzados con un promedio de 7.0 a 9.0 en las cuatro repeticiones, fueron identificados como muy precoces.

En total se seleccionaron 13 clones muy precoces (7-9), con un rendimiento mayor a $20 \mathrm{tn} / \mathrm{ha}$, como se muestra en la Tabla SP.3. Este resultado nos indica la factibilidad de reducir el período vegetativo del camote para su cultivo en zonas áridas y riego restringido. Este material sería utilizado como control para otros experimentos de precocidad. A solicitud del Instituto de Agronomia de la Universidad Tarapaca, Chile, estos clones selectos están siendo introducidos al sistema de cultivos in vitro para su limpieza de patógenos y exportación para pruebas experimentales en las zonas áridosalinas del desierto de Atacama, Chile.

\section{LIMPIEZA DE VIRUS DE LOS CLONES SUPERIORES}

Los clones superiores, candidatos a variedades, antes de ser liberados fueron sometidos al sistema de cultivo in vitro para la limpieza de virus y otros patógenos, consiguientemente la micropropagacion masal. Estos clones se encuentran hoy almacenados en el Banco Internacional de Germoplasma in vitro de papa y camote del CIP. Después de la obtención de plántulas in vitro, fueron liberados conjuntamente para la agricultura nacional por la UNTAC y el CIP en el campus de la Universidad de Tacna (Chávez et al 1994). Duplicados de plántulas in vitro que pasaron a pruebas de ELISA (negativos) para los principales virus de la papa, fueron enviados por el CIP a la Universidad Nacional de Tacna para su conservación y micropropagación masal. 


\section{RESISTENCIA A ESTRESES BIÓTICOS PREDOMINANTES EN ZONAS ÁRIDAS}

Dentro de la estrategia del mejoramiento genético se ha logrado la obtención de algunos clones con potencial forrajero y clones con resistencia al nemátodo del nudo de la raíz Meloydogine, así como a los virus más comunes de la papa.

\subsection{RESISTENCIA A NEMÁTODOS}

El estrés biótico más importante en el cultivo de la papa y del camote en zonas árido-salinas de la costa peruana, es el ataque del nemátodo del nudo de la raíz, constituido por poblaciones de tres especies, M.incógnita, M.javanica y M.arenaria. Genotipos susceptibles a estas plagas son eliminados en el programa de mejoramiento y adaptación. La indicación de susceptibilidad del camote a Meloidogyne incluye nodulaciones en la raíz, necrosis, producción masal de huevos o quistes, rajaduras o deformaciones de la raíz reservante. clorosis y crecimiento retardado o enanismo y reducción del rendimiento. Por eso es importante que cualquier clon mejorado o variedad de camote liberada, sea resistente a las razas virulentas de Meloidogyne.

Estas tres especies de Meloidogyne parecen - producir un sinergismo en el ataque a los cultivos de papa y camote de la costa peruana (P.Jatala, 1992). Previos estudios indican que la resistencia al nemátodo del nudo de la raíz es multifactorial. La selección de los genotipos parentales para policruzas se basa en la combinación de caracteres asociados a alto rendimiento, buena calidad comercial de raíces reservantes, tolerancia al estrés abiótico de sequia y salinidad y resistencia a Medaloidogyne. Jones y Dukes (1980) plantearon la hipótesis de que existen factores genéticos comunes que controlan la resistencia a estas tres especies de Medaloidogyne. Por otra parte, los estimados de heredabilidad para la reacción a estas especies son altos. Asimismo, la frecuencia de resistencia a las pruebas de progenie indican que el desarrollo de variedades resistentes a ambas especies seria relativamente fácil. Sin embargo, será necesario seleccionar para cada especie en forma independiente (Jones, 1980).

La experiencia nos muestra que el nivel de la población de nemátodos, llega al máximo durante los meses de verano. Es por eso que el tamizado óptimo de progenies y clones promisorios de camote se debe hacer entre noviembre y marzo. Los clones de papa antes de ser tamizados deben tener previamente resistencia genética al calor. Sin embargo, se han obtenido tamizados satisfactorios de poblaciones de papa y camote en la costa sur peruana en primavera media y tardía, y en otoño temprano y medio. Esto se recomienda para clones de papa que no son tolerantes al calor de verano.

Cada año, las poblaciones nuevas de papa y camote son tamizadas para resistencia al nemátodo. Durante la cosecha de cada experimento de papa y camote, se selecciona primero, en el campo, los clones para su performancia agronómica y luego en esta población seleccionada, se hace el tamizado y descarte de clones susceptibles al nemátodo. Asimismo se ha logrado seleccionar progenitores con buena habilidad combinatoria para resistencia a las tres especies de nemátodo.

\subsection{RESISTENCIA GENÉTICA A VIRUS}

Los virus ocasionan grandes pérdidas de rendimiento a la papa. Las plantas infectadas con virus producen tubérculos más pequeños que las plantas sanas. Estos tubérculos, al ser empleados como semilla, en las siguientes campañas generalmente producen plantas infectadas, contribuyendo a una degeneración progresiva y total del cultivo.

Se conocen aproximadamente unos 25 virus diferentes y un viroide que infecta la papa en condiciones naturales. Causan diferentes sintomas en hojas, tallos y tubérculos, entre ellos mosaico, amarillamiento, moteado, necrosis, enrrollamiento de hojas, deformación del tubérculo. Estos síntomas son producidos mayormente por los virus de la papa, PVX, PVY, PLRV, PVA, APMV y APLV. (Salazar 1996). Cerca de diez especies de áfidos han sido identificados en los valles de Tacna que habitan mayormente en especies (8) de malezas halófitas muy comunes, que sirven como hospederos (Guerra Cy R. Zegarra, 1993). Por otra parte, poblaciones de áfidos son detectadas en los cultivos y terrenos abandonados de papa, camote, aji, algodón, maíz y tomate. Esto origina una fuerte presión de población a los nuevos cultivos de papa, produciendo una efectiva infección a los clones sometidos a evaluación. Se ha observado que 
cualquier variedad o clon avanzado (que no es resistente a virus) cultivado en la costa surperuana (Tacna, Moquegua y Arequipa), muestra síntomas de enfermedad virótica en la siguiente campaña, reduciendo el vigor y el rendimiento, mostrando una "degeneración" en la variedad en pocos meses o campañas agrícolas.

Una variedad superior adaptada a las condiciones de aridez, salinidad, calor y con buenos caracteres agrónomicos, no tendría durabilidad ni futuro sino resistencia a los virus más comunes, en un medio agroecológico con alta infección virótica. Este criterio no sólo es para la costa sino para la sierra semiárida del sur del Perú.

Uno de los mayores logros del proyecto de mejoramiento genético en papa para el Tercer Mundo, ejecutado por el departamento de Genética y Mejoramiento del Centro Internacional de la Papa, ha sido la transferencia de genes de resistencia a los principales virus de la papa a clones superiores. De esta manera, se ha logrado generar clones mejorados, inmunes a los virus PVY y PVX y clones resistentes al virus PLRV. En este sentido, el germoplasma mejorado de papa para zonas árido-salinas involucra algunos clones inmunes a PVY y PVX y resistencia (aunque en menor grado) al virus PLRV.

Durante los últimos cinco años se ha sometido a 34 clones élites de papa, resistentes a estreses abióticos, a una fuerte presión de selección para resistencia a virus. Los clones fueron cultivados experimentalmente en chacras de agricultores durante cinco a siete generaciones clonales, sin reciclar la semilla en la sierra ni en invernaderos, es decir, se utilizó la misma semilla. La observación de los síntomas generados por los virus en papa, en los clones élites comparados con las variedades convencionales, se realizó en cada campaña. Se identificó 16 clones de alta resistencia de campo a los virus del mosaico PVX, PVY y cuatro clones altamente resistentes a los seis virus estudiados (P.VX, PVY, PVA, APMV, APLV). Por otra parte, las variedades convencionales usadas como control: REVOLUCION, MARIVA, TOMASA y PERRICHOLI, mostraron alto grado de infección después de la 2da. y 3ra. generación clonal.

En relación a las enfermedades viróticas del camote, Moyer y Salazar L. (1989) reportaron la identificación de cuatro principales virus que atacan a plantas de camote, siendo el más importante, desde el punto de vista económico, el virus del moteado plumoso (SPFMV). Hasta ahora no se ha podido detectar síntomas de enfermedades viróticas en los clones evaluados para resistencia a estreses abióticos. Tal vez los síntomas que producen los efectos tóxicos de salinidad, niveles elevados de boro y sequía, camuflan los síntomas de virus. Algunos clones promisorios, resistentes a SPFMV, generados por el departamento de Virología del CIP, no han tuberizado bajo condiciones de suelos áridos y salinos. Sin embargo, estos clones han sido utilizados por el departamento de Genética del CIP, como donantes de genes de resistencia a este virus, en programas de cruzamiento.

El programa de cruzamiento de selección clonal ha permitido desde el principio del proyecto la generación de clones promisorios tolerantes a salinidad. En este sentido, se ha venido ampliando la base genética gradualmente, hasta llegar a una población avanzada de cerca de 600 clones promisorios, adaptados a las condiciones áridosalinas y con buenas caracteres agronómicos.

Sin embargo, a través del tiempo se ha venido descartando muchos clones que inicialmente en los primeros años, fueron seleccionados como promisorios y resistentes a estreses abióticos, debido a su inestabilidad en performancia agronómica general. No se descarta la posibilidad que esta inestabilidad se deba a la acción acumulativa del virus de moteado plumoso. En este sentido, se ha iniciado el programa de ensanchamiento de la base genética del germoplasma, mejoramiento de camote, con genes de resistencia a este virus.

\section{GANANCIA GENÉTICA}

A pesar de la baja heredabilidad del camote para resistencia a estreses abióticos en zonas árido-salinas se ha logrado un avance de selección en las nuevas poblaciones generadas. Hasta ahora los resultados sobre evaluación de clones mejorados para tolerancia a suelos árido-salinos, ilustran el potencial que tiene el cultivo de la papa y el camote para adaptarse a suelos marginales desérticos, donde hay poca disponibilidad de agua de riego (Tabla PO.2)

Desde inicios de 1985 hasta el invierno de 1996 se han evaluado, bajo condiciones árido-salinas más de 30000 híbridos avanzados de papa y más de 80000 genotipos promisorios de camote. Como resultado de 
esta investigación, se han seleccionado 154 clones avanzados de papa y cerca de 600 clones promisorios de camote, tolerantes a salinidad y sequía.

Esta adaptación ha sido verificada en varios experimentos bajo condiciones de primavera, verano, otoño e invierno en la costa sur peruana. Estos genotipos promisorios sobreviven bajo condiciones de salinidad y riego restringido, mientras que sucumben a estos estreses. La adaptación a estas condiciones edáficas, también implica la tolerancia a toxicidad de boro y otros estreses diferentes a la salinidad, tales como deficiencias en nitrógeno, fósforo y zinc, propios de los suelos desérticos del sur del Perú. De los 600 clones promisorios de camote, se han seleccionado 65 mejores clones élites por su estabilidad a través de numerosos experimentos de rendimiento y performancia agronómica y en diferentes localidades. De estos clones élites, 10 han entrado al proceso de cultivo in vitro para su limpieza de virus, micropropagación y distribución a los sectores productivos del país y del extranjero.

Los clones tolerantes a salinidad y sequia han mostrado rendimientos superiores a $20 \mathrm{tn} / \mathrm{ha}$, bajo condiciones de verano y en un ciclo vegetativo de $90 \mathrm{y}$ 120 días en papa y camote respectivamente. fluctuando la salinidad del suelo irrigado durante el crecimiento de la papa de 5 a $15 \mathrm{mmh} / \mathrm{cm}^{2}$. Los clones élites de camote mejorado han mostrado, a través del tiempo y del espacio, una resistencia genética de campo a las razas virulentas de Tacna del nemátodo del nudo de la raíz, Meloidogyne incognita, M.javánica y M.arenaria.

El germoplasma élite de camote está actualmente constituido por un caudal de clones mejorados que han mostrado buena performancia agronómica, bajo una presión de selección por estrés abiótico, a través del tiempo y en diferentes localidades de la costa peruana. En este sentido, ha habido una ganancia genética expresada en rendimiento de toneladas por hectárea. Estos clones de camote, así como de papa, fueron cultivados en áreas donde la producción comercial de estos cultivos sería casi imposible, sin la previa tolerancia genética a la salinidad y otros estreses edáficos propios del desierto.

Otros caracteres agronómicos comunes de este germoplasma mejorado, son también su gran precocidad y rangos altos de materia seca que lo hacen promisorio para procesamiento industrial. Todos los clones mejorados de papa son tolerantes al calor, debido a que las evaluaciones y selecciones han sido realizadas bajo condiciones de primavera tardía y verano. Además, de estos atributos de adaptación, las variedades de papa desértica tienen excelente calidad industrial que lo hacen potenciales para la agroindustria mediante un suministro sostenido y todo el año de materia prima. En este sentido, la Universidad Nacional de Tacna y el Centro Internacional de la Papa, en forma conjunta, han liberado las mejores variedades superiores de camote y papa, adaptadas a esta zona agroecológica, común en la costa peruana (Tablas SP. 1, 2, 3 y PO. 1, 2, 3).

\section{SELECCIÓN IN VITRO PARA RESISTENCIA A SALINIDAD}

Pruebas experimentales in vitro con diez clones superiores de camote y diez clones avanzados de papa, han mostrado una correlación moderada entre la resistencia a salinidad en el campo y la resistencia a salinidad bajo condiciones de cultivo in vitro. Clones que tienen buena performancia agronómica bajo condiciones edáficas de salinidad hasta $12 \mathrm{mmhs}$, no sobreviven o se muestran latentes bajo condiciones in vitro a una concentración de 12 mmhs. La formación de callos en plantas y clones sobrevivientes, parece ser un indicativo de reacción de resistencia al fuerte estrés de salinidad.

Una de las limitaciones en los tamizados para resistencia a salinidad o toxicidad de boro, bajo condiciones de cultivo in vitro, son las diferencias clonales de respuesta al cultivo in vitro. Algunos clones de papa y camote presentan dificultades para su crecimiento y micropropagación.

\section{MECANISMO DE RESISTENCIA GENÉTICA AL ESTRÉS ABIÓTICO}

Las diferencias genotípicas en la tolerancia a estreses abióticos, producidas por la salinidad y toxicidad del boro, se deben a la variabilidad genética en el grado de eficiencia de absorción y transporte de los iones en la planta. En este sentido, la tolerancia a la salinidad y toxicidad de boro, así como el estrés de sequía, son poligénicamente controlados. La reacción a salinidad en papa y camote no es simple. Generalmente hay una correlación negativa entre tolerancia al calor y sequía con la tolerancia al frío.Por consiguiente, clones selectos para buena performancia en calor y sequía, no tienen buena performancia en frío y viceversa. 
El mecanismo de tolerancia de las plantas de papa y camote a la salinidad, se debe a la resistencia de cambios en la ultra estructura de los cloroplastos de las hojas de la planta por el estrés de sal que presumiblemente afectan a la performancia de asimilación y capacidad fotosintética de la planta y a la producción de carbohidratos. Asimismo, a la habilidad de las células de la planta a tolerar altos niveles de sodio. Según Epstein 1980, las diferencias en la captación o ingreso de iones, o transporte de ellos, es importante en el mejoramiento para tolerancia a salinidad.

El mejoramiento genético para tolerancia a salinidad, ha sido llevado a cabo exitosamente en otros cultivos. Bains y asociados (1971) encontraron que las líneas mejoradas de cebada, tolerantes a salinidad, tenian una reducción de $39 \%$ del rendimiento, cuando se aumentaba la salinidad de 8 a $34 \mathrm{mmhs} / \mathrm{cm}^{2}$. Bains desarrolló variedades de cebada que pueden ser irrigadas con agua de mar, con un rendimiento del $50 \%$ menor que el promedio nacional en la India.

Epstein y C. Rick en (1976) y Rick (1982) reportaron la tolerancia a salinidad de híbridos interespectivos de tomate, que puedan dar frutos aceptables con $33 \%$ de agua de mar. EPSTEIN planteo la hipótesis que la resistencia a salinidad en el tomate está asociada a la habilidad de las células a tolerar altos niveles de sodio o translocación de los mismos. Epstein y Lauchli (1980) plantearon la hipótesis que las diferencias a la captación o ingreso de iones, asi como el transporte de ellos, es importante en el mejoramiento para la tolerancia a la sal.

A. Quinn en 1980 reportó la selección de variedades de remolacha azucarera, tolerantes a salinidad para las zonas áridas de Estados Unidos. Quinn (1980) planteó la hipótesis que el mecanismo de resistencia a salinidad es debido a la exclusión selectiva de iones de sodio. De igual manera, se puede enumerar ejemplos de tolerancia a salinidad en variedades mejoradas de caña de azúcar y arroz en el sudeste de Asia tropical.

\section{Analizando los planteamientos de} Pomannperoma (1982) Epstein y Lauchli (1982), podemos concluir que las diferencias genéticas en la tolerancia al estrés edáfico, producido por salinidad, acidez, toxicidad de boro, aluminio y hierro, se deben a la variabilidad genética de la especie cultivada en relación a cinco factores principales:
1. La absorción de iones por la raíz.

2. La traslocacion de los elementos dentro del xilema.

3. La retención de los iones en los tejidos adyacentes.

4. La movilidad de los elementos del floema.

5. La eficiencia en la utilización del metabolismo de iones.

Correlacionando estos principios teóricos, podemos decir que una plántula o esqueje de papa o camote, plantada en suelos salinos, presenta los siguientes cuadros:

\begin{tabular}{|c|l|}
\hline CLASE & \multicolumn{1}{|c|}{ REACCIÓN FENOTIPICA } \\
\hline 1 & $\begin{array}{l}\text { Sucumbe al ser trasplantado. } \\
2\end{array}$ \\
3 & $\begin{array}{l}\text { Sobrevive mostrando un enanismo y clorosis. } \\
\text { Desarrollo de la planta, mostrando quemaduras } \\
\text { en los bordes de las hojas y ninguna o muy poca } \\
\text { tuberización. } \\
\text { Desarrollo normal y vigoroso del follaje pero muy } \\
\text { poca o ninguna tuberizacion, no formación de } \\
\text { raices reservantes. } \\
\text { Desarrollo escaso del follaje y tuberización nor- } \\
\text { mal. } \\
\text { Desarrollo vigoroso del follaje y tuberización nor- } \\
\text { mal. }\end{array}$ \\
\hline
\end{tabular}

Dentro de la estrategia del proyecto, los clones promisorios seleccionados han sido de clase 5 y 6 . La primera permite una mayor densidad de siembra y mayor rendimiento. La segunda (clase 6) permite una cobertura rápida y eficaz del suelo, con el consiguiente ahorro de humedad edáfica y fluctuación moderada de los niveles tóxicos de salinidad.

\section{LIBERACIÓN DE VARIEDADES MEJORADAS}

Las características agronómicas generales de las variedades superiores liberadas para la agricultura de la costa peruana, han sido estudiadas y se mencionan a continuación. Sin embargo, es necesario una caracterización isoenzimática para una identificación precisa ("huella genética") de clon liberado.

a) Tolerancia a los factores adversos de muchos suelos de la costa, tales como salinidad (6-13 mmh) niveles elevados de boro (5-12 ppm.) y sequia parcial b) (riego restringido).

b) Potencial de rendimiento mayor de $20 \mathrm{tn} / \mathrm{ha}$ en un período vegetativo de sólo 120 dias en camote y 90 dias en papa.

c) Resistencia de campo al nemátodo del nudo de la raíz Meloydogine incognita, M.javánica y M.arenaria, el cual es una plaga común que ataca a las plantas tuberiferas de la costa peruana. 
M.arenaria, el cual es una plaga común que ataca a las plantas tuberíferas de la costa peruana.

d) Además, las variedades de papa tienen tolerancia al calor y resistencia a los virus del mosaico de la papa PVX y PVY, al virus del enrrollamiento de la hoja (PLRV), muy comunes y virulentos en el extremo sur de la costa peruana.

e) Buena y excelente calidad para procesamiento industrial.

\subsection{VARIEDADES SUPERIORES DE CAMOTE DISPONIBLES PARA ZONASÁRIDO-SALINAS DEL PERÚ (CARACTERISTICAS ESPECIALES)}

\section{Variedad Yarada}

De múltiple propósito: forraje, agroindustria y consumo directo. Con cerca de $40 \%$ de materia seca y de sabor moderadamente dulce, ideal para la panificación. Buena capacidad de almacenamiento. Follaje abundante y cobertura rápida del suelo a los 90 días.

\section{Variedad Nacional}

Para la agroindustria: Chips, harina, hojuelas, etc. Con un $34 \%$ de materia seca y sabor moderadamente dulce. Tiene un alto índice de cosecha, se adapta también a la selva media.

\section{Variedad Tacna}

Agroindustria y consumo directo. Con un $26 \%$ de materia seca y sabor dulce. Bajo fuerte presión poblacional es susceptible al nematodo. Es una variedad de excelente rendimiento en la costa, en altitudes que fluctúan entre 500 y 1500 m.s.n.m.

\section{Variedad Caplina}

Adecuada para harinas o almidón y consumo directo. Con un $39 \%$ de materia seca y sabor moderadamente dulce. Puede ser cultivada con buenos rendimientos económicos en la costa durante todo el año, inclusive en invierno, por su tolerancia al frío.

\section{Variedad Atacama}

Variedad de múltiples propósitos: forraje, agroindustria y consumo directo. Con un $26 \%$ de materia seca y sabor moderadamente dulce. Buena capacidad de prendimiento en siembras durante el invierno.

\section{Variedad Costanero}

Con un alto contenido de caróteno (promotor de vitamina A), ideal para la agroindustria (industrias de helados). Con un $22 \%$ de materia seca y sabor poco dulce. Altamente tolerante a toxicidad de boro.

\section{Variedad Salyboro}

De doble propósito: alimentación y forraje. Las hojuelas o chips de esta variedad son de buena calidad, con un $27 \%$ de materia seca y sabor dulce. Su palatabilidad es buena, sancochada, al horno y en frituras. Presenta un rendimiento comercial aceptable en la época de invierno.

\section{Variedad Comensal}

Variedad de uso múltiple: forraje, alimentación y agroindustria. Su palatibilidad es muy buena, sancochada en el horno y en frituras y con buena calidad de hojuelas o chips. Con un $29 \%$ de materia seca y de sabor muy dulce. Presenta un rendimiento comercial aceptable en la época de invierno y buena capacidad de almacenamiento. Altamente tolerante a sequía.

\section{Variedad Untacip}

(No liberada). Por su textura, color y alto contenido de materia seca, lo hace un buen candidato para la elaboración de helados con sabor a lucúma. Es una de las variedades de alto índice de cosecha (0.6-0.7). Muy resistente a sequía y de gran estabilidad en el tiempo y espacio. Puede rendir cuatro cosechas al año en la costa peruana, pudiendo ser sembrado y cosechado en cualquier día del año. Ha sido introducido al sistema in vitro para su limpieza de virus.

\section{Variedad Basadre}

(No liberada). De excelente textura y alto porcentaje de materia seca (32\%). Soporta altas densidades de siembra, debido a su elevado indice de cosecha (0.65-0.75). Buena variedad para hojuelas fritas (chips). Es moderadamente resistente a sequia y susceptible al ataque de ácaros (Tetraninchus sp.) Buena capacidad de almacenamiento.

13.2 VARIEDADES SUPERIORES DE PAPA DISPONIBLES PARA ZONAS ÁRIDO-SALINAS DEL PERÚ (CARACTERÍSTICAS ESPECIALES) 


\section{Variedad Costanera}

Papa tolerante al calor, por lo que se le puede cultivar en primavera, verano, otoño e invierno. Inmune a los virus PVX y PVY y moderadamente resistente a los virus PLRV. Es la primera variedad para las condiciones de la costa peruana, trópico húmedo medio y bajo, y la sierra media. De gran precocidad y tolerancia a la marchitez bacteriana. Con $21,6 \%$ de materia seca y de excelente calidad de hojuelas o chips, frituras y comercialización en forma de papa frita y congelada. De flores muy blancas y poca o ninguna formación de bayas.

\section{Variedad Tacna}

Papa también tolerante al calor, semejante a la variedad costanera, inmune a los virus PVX y PVY y muy buena resistencia al PLRV, moderadamente resistente al nemátodo del nudo y algo tolerante a la marchitez bacteriana. Esta variedad se adapta a las condiciones de la costa central y sur y a la zona subtropical media. Con $20,5 \%$ de materia seca y buena calidad de hojuelas o chips de frituras y comercialización en forma de papa frita congelada. Follaje abundante, pubercente y hábito de crecimiento muy definido.

\section{Variedad Basadre (Por liberar)}

Clon élite precoz y tolerante al calor, salinidad y sequía parcial. Este clon de pulpa amarilla ha sido varias veces evaluado junto con la variedad Desiree a nivel nacional, habiendo superado en todos los experimentos demostrativos. Tiene un rendimiento de 20-25 tn/ha en sólo 90 días y es inmune al virus PVX, PVY y resistencia de campo a PLVR. Proviene del cruzamiento de la Vr. Mexicana de alto rendimiento MEX.32 por el clon élite peruano, resistente a virus XY.9.

\section{Variedad Desértica (Por liberar)}

Clon élite sumamente precoz y altamente tolerante al calor, salinidad y sequía parcial. Adaptada a las condiciones desérticas. Es la variedad de mayor potencial de rendimiento bajo condiciones de verano $25-30 \mathrm{tn} / \mathrm{ha}$ en 90 días. Alta calidad de hojuelas y papas fritas. Ideal para la agroindustria. Resiste a los virus más comunes y proviene del cruzamiento de clon peruano, resistente a los virus $\mathrm{XY}$, por un clon de alta precocidad y tolerante al calor.

\section{Variedad Primavera (Por liberar)}

Clon élite precoz y altamente tolerante al calor, salinidad, sequía y niveles moderados de boro edáfico. Desarrollada para su adaptación a condiciones áridas y semiáridas de la costa y sierra surperuana. Es la variedad de mayor resistencia a los virus PVX, PVY, PLRV, APMV. Con gran porcentaje de materia seca y excelente textura para procesamiento industrial, especialmente papa a la francesa y hojuelas. Rendimiento superior a $25 \mathrm{tn} / \mathrm{ha}$, obtenido en primavera y verano. Proviene del cruzamiento del clon mejorado B.71.49.12 de alto rendimiento, con el clon mejorado XY.13, resistente a los virus y tolerante al calor y de mayor precocidad. Este clon ha sido incorporado al sistema de cultivo in vitro.

\section{PROSPECCIÓN FUTURA}

El estrés de sal probablemente cause más daño a las plantas, en términos de pérdidas económicas, que otro factor de estrés abiótico. Además, sus efectos son difíciles de detectar y su daño fisiológico es elusivo. Una razón fundamental para ejecutar trabajos de mejoramiento genético de plantas para estrés ambiental, es que mucho de la expansión de los cultivos en el Tercer Mundo en el futuro, será en suelos marginales, no adecuados para una agricultura comercial intensiva.

Modificando o controlando el medio ambiente es otra alternativa para controlar la salinidad. La interrelación genética-medio ambiente puede ser optimizada a través de estudios de mejoramiento genético de la planta con prácticas culturales, tal como se puede mostrar en estos experimentos con clones tolerantes a salinidad bajo riego por exudación. En el sistema de riego tecnificado, ya sea por goteo o exudacion, hay un ahorro extraordinario de agua, además, mantiene el cultivo bajo estrés moderado por el suministro permanente y suficiente de humedad. Por consiguiente, un manejo integrado de los suelos arido-salinos de potencial agrícola, engloba la utilización de un riego tecnificado que proporciona un gran ahorro de agua, gran incorporación de variedades mejoradas, tolerantes a salinidad y sequía.

Se calcula que en la próxima década, los agricultores expandirán su frontera agrícola hacia suelos marginales, cuando estas áreas sean el último recurso para la producción de alimentos en el Tercer Mundo, con una explosión demográfica creciente. 
Nosotros pensamos que la explotación del potencial de papa y camote, desarrollando nuevas variedades adaptadas a estos suelos marginales, irá paralela a la amipliación de la frontera agrícola en el desierto de la costa peruana.

La demanda mundial de alimentos significa que más cultivos deben realizarse en zonas marginales, lo cual conlleva a problemas de estrés abiótico. Los suelos marginales presentan serios problemas de salinidad, acidez, alcalinidad, deficiencia de minerales $y$ toxicidad de elementos como boro, aluminio y hierro. Mejorar las plantas para tolerancia a estreses abioticos y con buenos caracteres agronómicos, son dos caminos para incrementar la producción agrícola. En este sentido, el caudal genético de la papa y el camote ofrece una valiosa heredabilidad variable para el mejoramiento de resistencia al estrés. Esta variabilidad ha empezado a ser explotada en las zonas árido-salinas del desierto sur peruano.

Desde el inicio del proyecto de investigación colaborativa en 1995, hasta hoy dia, siempre hemos tenido en mente aplicar el principio universal técnico y moderno de: "El principal objetivo de la investigación fitogenética es obtener beneficios económicos de la superioridad heredable o de una combinación favorable de genes".

\section{NUEVAS HIPÓTESIS PLANTEADAS}

Durante los once años de investigación en mejoramiento de papa y camote se han generado cerca de 600 clones promisorios resistentes a estreses abioticos y con buenas características agronómicas. Observaciones realizadas en experimentos de campo y ocasionalmente en invernaderos, conducen a plantear algunas hipótesis en el mejoramiento de papa y camote para zonas árido-salinas, para su análisis futuro. Estas hipótesis se resumen en lo siguiente:

1. Existe una correlación entre la resistencia a salinidad y la resistencia a sequía. Los clones avanzados, resistentes a salinidad, muestran también una marcada resistencia a sequía o riego restringido.

2. No existe correlación entre la resistencia a salinidad

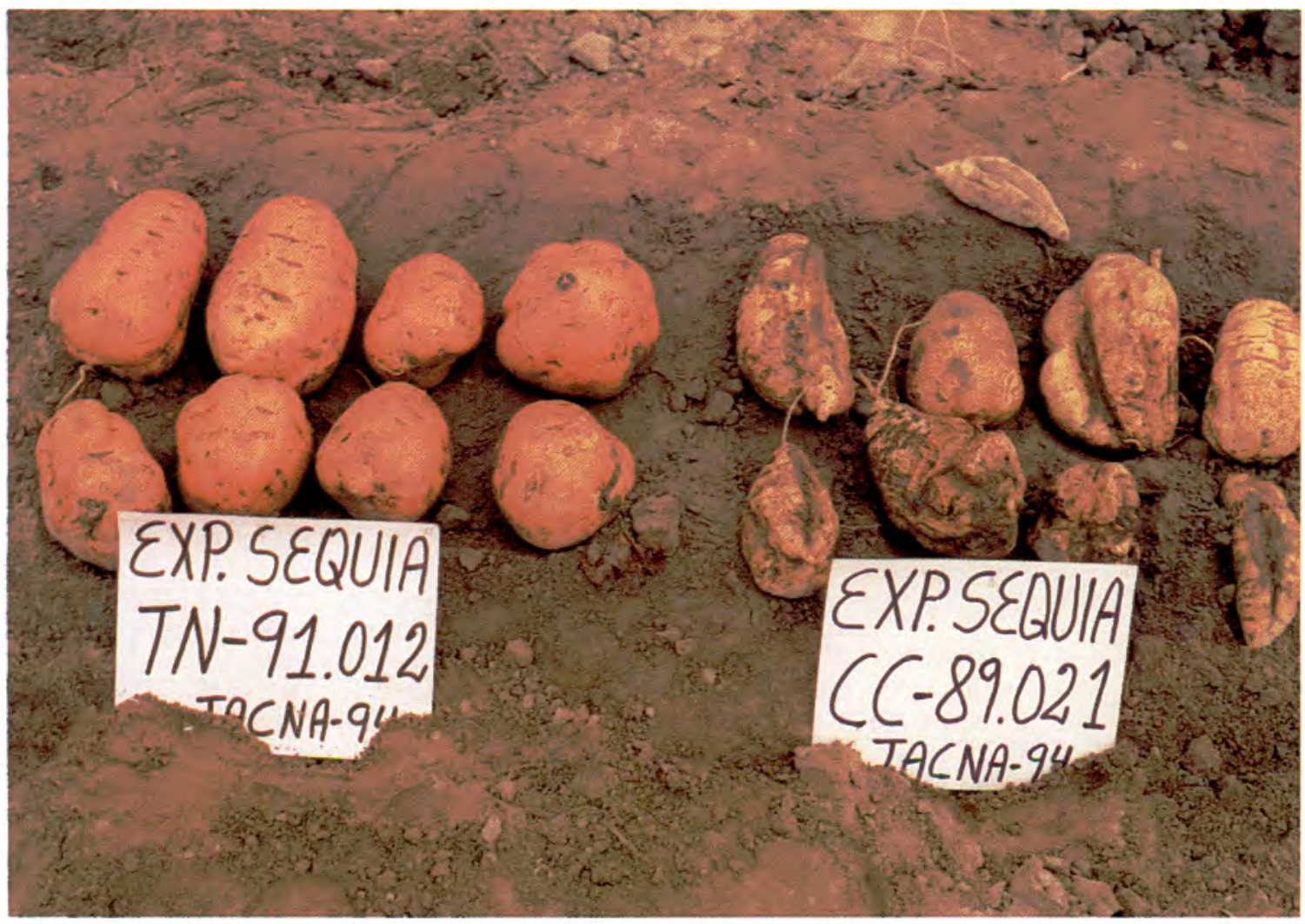

Los clones élites TN91.012 (UNTACIP) y CC89.021 (ITE) tienen alta resistencia a salinidad, sequía y toxicidad de boro, sin embargo, el clon CC-89.021 es susceptible al nemátodo M. incognita, cuya plaga deteriora la calidad del camote. 
con la resistencia al nemátodo del nudo de la raíz, M.incognita(RKN). Muchos clones promisorios y avanzados con resistencia a los estreses abióticos (salinidad, boro y sequia) han sido descartados por su susceptibilidad al ataque de RKN.

3. Existe una correlación negativa entre el contenido de materia seca y caróteno en el camote. Los clones con mayor cantidad de caróteno (grado 7 y 8 ) presentan menor contenido o porcentaje de materia seca, en relación con otros clones de diferente tipo de pulpa.

4. Existe cierta correlación negativa entre el contenido de azúcar y el contenido de caróteno en el camote. Los clones de mayor contenido de caróteno (grado 7 y 8) presentan un menor porcentaje de azúcares.

5. Hay una tendencia de los clones de camote de bajo rendimiento, pero alto grado de indice de cosecha con poco vigor, de mostrar mayor frecuencia en el grado de floración.

6. Hay una correlación muy baja entre la resistencia a estreses abióticos a nivel de plantula (genotipo o seedlings) y la resistencia a nivel de generaciones clonales, como se observa en el siguiente ejemplo:

\begin{tabular}{|c|c|c|}
\hline $\begin{array}{c}\text { GENERACIONES } \\
\text { CLONALES }\end{array}$ & $\begin{array}{c}\text { GENOTIPOS } \\
\text { DE CAMOTE }\end{array}$ & $\begin{array}{c}\text { CLONES } \\
\text { SELECCIONADOS }\end{array}$ \\
\hline 1er. Año a & $16000^{*}$ & 960 \\
2do. Año b & 960 & 450 \\
3er. Año c & 450 & 135 \\
4to. Año d & 135 & 53 \\
5to. Año e & 53 & 24 \\
6to. Año $f$ & 24 & 15 \\
\hline
\end{tabular}

* Seedlings (genotipos)

7. En cultivo de camote in vitro hay cierta correlación entre la resistencia a salinidad y la formación de callo a nivel de la base del tallo de la planta.

8. Existe una correlación negativa entre el mayor vigor de la planta/follaje y el grado de floración en zonas áridas

9. Hay una correlación positiva muy baja entre el grado de vigor del follaje y el peso total de la raiz reservante o el tubérculo, bajo condiciones de suelos salinos.

10. No se ha detectado sintomas de enfermedad virótica en el germoplasma mejorado de camote. Sin embargo, la inestabilidad de algunos clones avanzados, resistentes a estreses, se deberia a la acción acumulativa del virus del moteado plumoso del camote (SPPMV)

11. No hay correlación entre el grado de clorosis, quemaduras de bordes de hojas por efecto de la toxicidad del boro edáfico y la capacidad de producción de raíces reservantes. Clones con vigor de grado 7 y 9 en el follaje, tuvieron grado 3 ó 5 de rendimiento de raices reservantes.

12. No hay correlación entre la resistencia a salinidad y la resistencia a toxicidad de boro. Parece que ambas resistencias están controladas por la acción de diferentes grupos de genes.

13. Los estreses abióticos en zonas árido-salinas afectan la calidad culinaria en los tubérculos de papa, sobre todo la acumulación de glicoalcaloides (solanina). Es necesario seleccionar clones "resistentes" a esta acumulación, la cual se ha detectado con mayor frecuencia en clones con tubérculos de pulpa amarilla.

14. El estrés de sequía en un estado avanzado del crecimiento de la planta de camote, favorece el rendimiento y calidad de las raíces reservantes.

15. Hay diferentes respuestas fenotípicas al efecto del fotoperiodo en los clones mejorados de papa, camote y en familias hibridas de semilla botánica de papa, especialmente en la latitud de $18^{\circ}$ sur, bajo condiciones de Tacna. Sin embargo, es posible generar variedades de papa y camote insensibles al fotoperiodo.

16. Parece existir una correlación entre el tipo de pigmentación de la piel del camote y la papa, con la reacción al ataque de RKN. La mayoria de los clones de papa de piel roja o rosada, muestran susceptibilidad de campo al ataque de RKN. En cambio, en el camote con raíces reservantes de piel blanca muestran mas susceptabilidad a RKN.

\section{GENERACIÓN DE SEMILLA DE CALIDAD DE CAMOTE Y DE PAPA LIBRE DE VIRUS PARA DISTRIBUCIÓN NACIONAL}

Para mantener la estabilidad genética de los clones de camote élites, se ha cambiado el sistema tradicional de multiplicación de esquejes por el de brotes de raices reservantes. En la selección de raices reservantes se toma un alto criterio morfológico propio y original del clon. Los ensayos de brotamiento de raices reservantes en substratos de arena, bajo condiciones de invernadero, han mostrado gran variabilidad genética en el grado de brotamiento en 
el germoplasma mejorado de camote. Hay clones (grado 9) que producen hasta 20 tallos por raíz reservante a los 30 dias después de la siembra. En la actualidad, la producción de semilla de camote se realiza mayormente mediante brotes de camotes seleccionados por su calidad.

En vista de la creciente demanda de semilla de las variedades mejoradas de papa y camote desérticas, por parte de los agricultores y semilleristas de la costa sur peruana, se inicio un programa para la generación de semilla de calidad libre de virus y otros patógenos, a partir de cultivo in vitro de tejidos de papa y camote. Diez clones élites de camote y ocho de papa fueron introducidos al sistema de cultivo in vitro, pręcedidos por el tratamiento de termoterapia, cultivo de neristemos, micropropagación y pruebas serológicas de ELISA, para determinar el buen estado sanitario de los propágulos. Este procedimiento inicial se realizó en los laboratorios de biotecnología del Centro Internacional de la Papa.

Inicialmente, seis variedades mejoradas de camote se sometieron a micropropagacion masal del material libre de patógenos (Tacna, Yarada, Salyboro, Atacama, Costanero y Nacional). Luego las plántulas in vitro fueron transplantadas a invernaderos $y$ multiplicados, usando la técnica de multiplicación rápida, desarrollada por el CIP en la zona húmeda de ceja de selva y calurosa de San Ramón (La Merced $1000 \mathrm{msnm}$ ). Un total de 1000 esquejes de propagación fueron traidas a Tacna para su posterior multiplicación en el campo experimental en La Yarada y distribución a los agricultores y estaciones experimentales de la región.

En el caso de la papa, ocho clones fueron limpiados de virus, dando resultados negativos en las pruebas de ELISA para los virus PVX, PVY, PLRV, APMV, PVA y APLV. Luego se entregó al presente proyecto dos tubos que contenian una plántula in vitro de cada variedad. (Tabla PO.3)

Este material fue masalmente micropropagado en el laboratorio de biotecnologia - sección papa, de la Universidad Nacional de Tacna. Las variedades inicialmente micropropagadas fueron TACNA, COSTANERA, BASADRE para generar semilla prebásica. Las plántulas fueron multiplicadas en condiciones de invernadero y transplantadas a camassubstratos de arena y musgo para la producción de tuberculillos (minitubers) y posterior multiplicación en el campo para la distribución de semilla. Actualmente, se ha obtenido un total de 2500 plántulas in vitro de cada una de estas tres variedades. El proceso continuará hasta lograr por lo menos unos 8000 Kilos de semilla básica de calidad, de cada variedad, para distribuir a los semillaristas-agricultores en Tacna, Moquegua y Arequipa. El control de calidad de la semilla prebásica, generada en los laboratorios se hará sistemáticamente usando las pruebas serológicas de ELISA para la detección de por lo menos los seis virus más comunes que atacan al cultivo de la papa en la costa peruana.
TABLA PO.1: Grado de floracióny fructificación de clones progenitores tolerantes a estreses abióticos, bajo condiciones de primavera y verano.

\begin{tabular}{|c|c|c|c|c|c|c|}
\hline Nro. & CLON & PEDIGREE & $\begin{array}{l}\text { COLOR DE } \\
\text { LAFLOR }\end{array}$ & $\begin{array}{c}\text { GRADO } \\
\text { DE } \\
\text { RCRACONN }\end{array}$ & $\begin{array}{c}\text { GRADO } \\
\text { DE } \\
\text { FRUCTF. }\end{array}$ & $\begin{array}{c}\text { OTRAS } \\
\text { CARACTERISTICAS }\end{array}$ \\
\hline 1 & SDC89.262 & SERRANA $\times$ LT 7 & BLANCO & 3 & 0 & PULPAAMARILLA \\
\hline 2 & SDC89.308 & YY.12 x 377964.5 & BLANCO & 5 & 0 & CALIZ MORADO \\
\hline 3 & SDC89.315 & YY.20 × 377964.5 & BLANCO & 9 & 9 & MUY PRECOZ \\
\hline 4 & SDC91.027 & $X Y .20 \times X Y .16$ & BLANCO & 9 & 9 & MUY PRECOZ \\
\hline 5 & SDC91.035 & C83.387 x LB.BK & VIOLETA & 7 & 7 & MUY PRECOZ \\
\hline 6 & SDC91.640 & $B 71.240 .2 \times X Y .16$ & BLANCO & 7 & 3 & MUY PRECOZ \\
\hline 7 & SDC92.018 & $387971.5 \times 387521.3$ & VIOLETA & 7 & 7 & PULPA AMARILLA \\
\hline 8 & SDC92.019 & $387971.5 \times 387521.3$ & BLANCO & 7 & 0 & MUY PRECOZ \\
\hline 9 & SDC92.132 & $387971.5 \times 387521.3$ & BLANCO & 7 & 5 & MUYPRECOZ \\
\hline 10 & SDC92.145 & $\mathrm{XY} .10 \times \mathrm{NDD} 277.3$ & BLANCO & 7 & 0 & PULPAAMARILLA \\
\hline 11. & SDC92.170 & SEDAFIN $\times X Y .3$ & VIOLETA & 7 & 7 & PULPA AMARILLA \\
\hline 12 & SDC92.172 & SEDAFIN $\times X Y .3$ & VIOLETA & 7 & 7 & PULPAAMARILLA \\
\hline 13 & SDC 387776.3 & BR6984 x Y 84.012 & VIOLETA & 7 & 9 & PULPA AMARILLA \\
\hline 14 & COSTANERA & LT.1 X XY.BK & BLANCO & 5 & 1 & MUY PRECOZ \\
\hline 15 & MARIVA(C) & MARITA $\times$ VACAPA & VIOLETA & 7 & 0 & MED. PRECOZ, MS \\
\hline
\end{tabular}

TABLA PO.2: Resistencia a sequia y calidad industrial de clones tolerantes a estreses abióticos. Primavera 1995, Pachía, $1000 \mathrm{msnm}$. Período vegetativo: 90 dias.

\begin{tabular}{|c|c|c|c|c|c|c|c|c|c|}
\hline \multirow[b]{2}{*}{ Nro. } & \multirow[b]{2}{*}{$\begin{array}{l}\text { CLON } \\
\text { SUPERIOR }\end{array}$} & \multirow[b]{2}{*}{ PEDIGREE } & \multicolumn{3}{|c|}{ RIEGO NORMAL } & \multicolumn{3}{|c|}{ ESTRES DE SEQURA } & \multirow[b]{2}{*}{$\begin{array}{l}\text { COLOR DE } \\
\text { LA PULPA }\end{array}$} \\
\hline & & & \begin{tabular}{|l|} 
NRO \\
ORDEN \\
\end{tabular} & $\begin{array}{c}\text { fenom } \\
\text { gpal }\end{array}$ & $\begin{array}{l}\text { CADE } \\
D E \\
\text { CHES } \\
\end{array}$ & \begin{tabular}{l|l|} 
NRO \\
ORDEN
\end{tabular} & 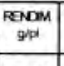 & $\begin{array}{c}C A D D \\
D E \\
D E \\
C H I P S \\
\end{array}$ & \\
\hline 1 & COSTA & LT.1 $x$ & 1 & 1008 & 7 & 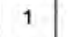 & 516 & 7 & \\
\hline 2 & SDC91.628 & SERRANA $\times X Y .11$ & 2 & 958 & 3 & 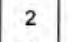 & 759 & 7 & CREM \\
\hline 3 & SDC92.019 & $797.5 \times 387521.3$ & 3 & 916 & 5 & 3 & 592 & 7 & CREMA \\
\hline 4 & SDC91. & 1.240 & 4 & 907 & 9 & ${ }^{4}$ & 612 & 9 & REMA \\
\hline 5 & SDC92.145 & $10 x$ & 5 & 893 & 3 & . & 510 & 9 & MARILL \\
\hline 6 & SDC92. & 38797 & 6 & 855 & 5 & 6 & 582 & 7 & CRE \\
\hline 7 & SDC89. & & 7 & 0 & 1 & ? & 78 & 3 & Now \\
\hline 8 & DESIREE & CONT & 8 & 724 & 7 & 8 & 626 & 7 & AMA \\
\hline 9 & SDC91.750 & & 9 & 677 & 3 & 9 & 11 & 5 & \\
\hline 10 & SDC89.3 & $X Y .20 \times 377964.5$ & 10 & 672 & 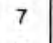 & 10 & 580 & 7 & CREMA \\
\hline 11 & TACNA. & SERRANA $\times X Y .4$ & 11 & 655 & 7 & 11 & 464 & 7 & CREMA \\
\hline 12 & SDC91.6 & & 12 & 654 & 5 & 12 & 425 & 9 & AMARILIO \\
\hline 13 & & & 13 & & 5 & 13 & 294 & 7 & CREMA \\
\hline 14 & TOMASA & CONTROLII & 14 & 391 & 1 & 14 & 164 & 3 & CREMA \\
\hline
\end{tabular}


TABLA PO.3: Cultivo IN VITRO de clones y variedades mejoradas de papa manejadas en el laboratorio de biotecnología sección papa. Facultad de Ciencias Agrícolas, fundo Los Pichones.

\begin{tabular}{|c|c|c|c|c|c|c|c|}
\hline$N^{\circ}$ & $\begin{array}{c}\text { CLON/ } \\
\text { VARIEDAD }\end{array}$ & PEDIGREE & $\begin{array}{l}\text { PLANTUAS } \\
\text { IN VITRO }\end{array}$ & ELISA & $\begin{array}{l}\text { MCROPRO } \\
\text { PAGACION }\end{array}$ & $\begin{array}{l}\text { TUBER. } \\
\text { CUULOS }\end{array}$ & $\begin{array}{l}\text { COLOR } \\
\text { PULPA }\end{array}$ \\
\hline 1 & BASADRE & MEX. $32 \times X Y .9$ & 1 & 1 & 1 & 1 & AMARLO \\
\hline 2 & COSTANERA & LT. $1 \times X Y$ X BULK & 1 & 1 & 1 & 1 & CREMA \\
\hline 3 & DESERTICA & $X Y .10 \times$ NDD 277.2 & 1 & 0 & 0 & 0 & AMARILO \\
\hline 4 & PRIMAVERA & $B 71,74.49 .12 \times X Y .13$ & 1 & 0 & 0 & 0 & AMARILLO \\
\hline 5 & REVOLUCION & NARANJA $\times(K \times M)$ & 1 & 1 & 0 & 0 & CREMA \\
\hline 6 & TACNA & SERRANA $\times X Y, 4$ & 1 & 1 & 1 & 1 & CREMA \\
\hline 7 & TOMASA & $(B 606 \times K) \times(R \times Y)$ & 1 & 1 & 1 & 0 & CREMA \\
\hline 8 & SDC91.640 & B71, $240.2 \times X Y .16$ & 1 & 1 & 1 & 0 & CREMA \\
\hline 9 & SDC92.140 & 387521.3 & 1 & 1 & 1 & 0 & AMARILO \\
\hline 10 & SDC91.172 & $\begin{array}{l}\text { APHRODITA } \\
\text { SEDAFIN } \times X Y .3\end{array}$ & 1 & 1 & 1 & 0 & CREMA \\
\hline
\end{tabular}

TABLA SP.1: Nuevos clones avanzados, tolerantes a estreses abióticos y resistentes al nemátodo Meloydogine, de alto grado de producción de cápsulas y semillas viables, bajo condiciones de primavera.

\begin{tabular}{|c|c|c|}
\hline NUNERO & CLON & PEDIGREE \\
\hline 1 & TN95.581 & SR92.623-POLY.94.TN \\
2 & TN95.598 & TN89.003-POLY.94.TN \\
3 & TN95.607 & TN89.131-POLY.94.TN \\
4 & TN95.624 & TN89.148-POLY.94.TN \\
5 & TN95.644 & TN90.044-POLY.94.TN \\
6 & TN95.660 & TN93.340-POLY.94.TN \\
7 & TN95.661 & TN92.340-POLY.94.TN \\
8 & TN95.662 & TN92.340-POLY.94.TN \\
9 & TN95.680 & TN92.386-POLY.94.TN \\
10 & TN95.682 & TN92.386-POLY.94.TN \\
11 & TN95.687 & LM92.081-POLY.94.TN \\
12 & TN95.698 & TN88.105-POLY.94.TN \\
\hline
\end{tabular}

\section{REFERENCIAS BIBLIOGRÁFICAS}

Chavez, R.; Upadhya, M.; Cabello R. Berrios, R.; Siles P. (1996). Producción de papa en zonas áridas y salinas a partir de semilla botánica Factibilidad y Perspectivas. Rev. Ciencia y Desarrollo Vol III 1996.

Chavez, R.H. Mendoza; J. Espinoza (1995) Breeding sweet potato for resistance to arid and saline soils. ABSTRACT "Vine to the Roots" 1995

Chavez,-R.; Mendoza, H.; Espinoza, J. (1995) Breeding sweet potato for adaptation to arid and saline soils. CIP, circular 1995, pp.2-6.

Chavez, R. (1995) Clones superiores de papa y camote adaptados a suelos áridos y salinos. Revista Ciencia y Desarrollo Vol. II 1995.

Chavez, R. (1993) Seis Nuevas variedades de camote para la costa peruana. Revista Nueva Imagen II. pp 3-9.

Chavez, R.; H. Mendoza; J. Espinoza; N. Arévalo; L. Diaz (1992). Estrategia y ganancia genética en el mejoramiento de papa y camote para zonas árido-salinas. Revista de investigación Nueva Imagen III. pp 4-16

Chavez A., H. Mendoza; J. Espinoza, J. Florez; J. Chavez; P. Siles, M. Huacollo (1994). Ampliando la base genética para resistencia a salinidad y sequia en el germoplasma mejorado de papa y camote. Rev. Nueva Imagen $\mathrm{N}^{\circ}$ IV, pp 13-27-A.

Guerra C. y Zegarra R. (1995) Afidos y hospederos naturales del valle de Tacna. Revista Ciencia y Tecnologia Vol II 1995.

Espinoza, J. Chavez y Mendoza H. (1986). Factibilidad de mejoramiento genético de papa en suelos salinos. Primer Congreso Peruano
TABLA SP.2: Resistencia al estrés de sequía en las variedades resistentes a salinidad y nemátodo Meloydogine. Localidad: La Yarada, primavera.

\begin{tabular}{|c|l|c|c|l|c|}
\hline \multicolumn{3}{|c|}{ RIEGO RESTRINGIDO (4 REP.) } & \multicolumn{3}{c|}{ ESTRES DE SEQUIA (20 REP.) } \\
\hline $\begin{array}{c}\text { N. DE } \\
\text { ORDEN }\end{array}$ & \multicolumn{1}{|c|}{ VARIEDAD } & $\begin{array}{c}\text { x PERFORM. } \\
\text { AGRONOMICA }\end{array}$ & $\begin{array}{c}\text { N } \\
\text { ORDEN }\end{array}$ & \multicolumn{1}{|c|}{ VARIEDAD } & $\begin{array}{c}\text { X PERFORM. } \\
\text { AGRONOMICA }\end{array}$ \\
\hline 1 & SALYBORO & 8.00 & 1 & UNTACIP & 6.13 \\
2 & YARADA & 8.00 & 2 & SALYBORO & 5.66 \\
3 & NACIONAL & 7.00 & 3 & COSTANERO & 5.12 \\
4 & UNTACIP & 6.75 & 4 & YARADA & 4.16 \\
5 & ATACAMA & 6.50 & 5 & CAPLINA & 3.99 \\
6 & GRANFORRANERO & 6.50 & 6 & ATACAMA & 3.83 \\
7 & CAPLINA & 6.00 & 7 & NACIONAL & 3.66 \\
8 & COMENSAL & 6.00 & 8 & GRANFORRAJERO & 3.48 \\
9 & COSTANERO & 6.00 & 9 & COMENSAL & 3.33 \\
10 & TACNA & 5.50 & 10 & TACNA & 2.99 \\
\hline
\end{tabular}

* Performancia agronómica basada en rendimientos por planta y calidad comercial de las raices reservantes.

TABLA SP.3: Nuevos clones promisorios, de alta precocidad y tolerantes a estreses abióticos. Periodo vegetativo: 90 dias, verano - otoño. Localidad: La Yarada, Tacna. 1996.

\begin{tabular}{|c|c|c|c|c|c|c|}
\hline NRO & CLON & COLOR PIEL & $\begin{array}{c}\text { COLOR } \\
\text { PULPA }\end{array}$ & $\begin{array}{c}\text { DISTRIBUCION } \\
\text { ANTHOCININAS }\end{array}$ & $\begin{array}{c}\text { GROSOR } \\
\text { CORTEZA }\end{array}$ & LATEX \\
\hline 1 & TN95.031 & 2 & 2 & 3 & 5 & 1 \\
2 & TN95.065 & 5 & 6 & 0 & 7 & 1 \\
3 & TN95.068 & 8 & 8 & 1 & 5 & 1 \\
4 & TN95.075 & 5 & 7 & 0 & 5 & 1 \\
5 & TN95.119 & 9 & 9 & 9 & 7 & 1 \\
6 & TN95.195 & 8 & 3 & 1 & 3 & 1 \\
7 & TN95.197 & 8 & 8 & 6 & 3 & 1 \\
8 & TN95.285 & 2 & 2 & 8 & 3 & 1 \\
9 & TN95.303 & 9 & 2 & 1 & 3 & 3 \\
10 & TN95.505 & 2 & 1 & 0 & 7 & 1 \\
11 & TN95.509 & 3 & 4 & 0 & 7 & 1 \\
12 & TN95.514 & 4 & 7 & 0 & 3 & 1 \\
13 & TN95.524 & 2 & 1 & 0 & 1 & 1 \\
14 & TN95.583 & 2 & 5 & 0 & 3 & 1 \\
15 & TN95.611 & 8 & 2 & 8 & 5 & 1 \\
\hline
\end{tabular}

Mendoza, $H_{\text {.; }}$ Chavez, R.,Espinoza,J.;Arévalo N. y Diaz L. Avances en el mejoramiento de papa para zonas árido-salinas. Congreso Latinoamericano de la Papa. Lima, Perú. 1991.

Jones, A. (1986). Estimados de heredabilidad en camote y su uso en mejoramiento. Horstcience Vol. 21 (1) Februeary, 1986.

Ponnamperuna. F.N. (1982). Mejoramiento de plantas cultivadas para tolerancia al estrés edáfico. En Plant improvement and. somatic cell genetics. Edit. Indra Vasil. Et al 1982.

Rick, C. (1982) El potencial del germoplasma exótico de tomate para el mejoramiento genético. En plant improvement and Somatic cell genetics. Edit. Indra Vasil. Et al 1982

Sindem, S.L. y R.E. Webb, 1974. Effect of enviroment on glycoalkaloid content of six potato varieties at 39 locations. Technical Bolletin No. 1472. USDA.

Salazar, L. F. (1996) Los virus de la papa y su control. Edit CIP 226 pp.

Thompson, P.G., Mendoza H.A. y plaisted.L.(1983) Estimación de parámetros genéticos relacionados a la propagación de la papa por semilla botánica en una población indigena. American Potato Journal, pp 393-401.

Thompson, P.G. y Mendoza H.A. (1984) Estimados de variancia genética en una población heterogénea de papa, propagada por semilla botánica. American Potato Journal. S. 